\title{
Manufacturing nanomaterials: from research to industry
}

\author{
Costas A. Charitidis*, Pantelitsa Georgiou, Malamatenia A. Koklioti, Aikaterini-Flora Trompeta, \\ and Vasileios Markakis
}

National Technical University of Athens, School of Chemical Engineering, Department III: Materials Science and Engineering, Research Unit of Advanced, Composite, Nano-Materials and Nanotechnology, 9 Heroon Polytechniou St., Zografos, Athens GR-157 73, Greece

Received 1 July 2014 / Accepted 25 July 2014

\begin{abstract}
Manufacturing of nanomaterials is an interdisciplinary field covering physics, chemistry, biology, materials science and engineering. The interaction between scientists with different disciplines will undoubtedly lead to the production of novel materials with tailored properties. The success of nanomanufacturing depends on the strong cooperation between academia and industry in order to be informed about current needs and future challenges, to design products directly transferred into the industrial sector. It is of paramount importance the selection of the appropriate method combining synthesis of nanomaterials with required properties and limited impurities as well as scalability of the technique. Their industrial use faces many obstacles as there is no suitable regulatory framework and guidance on safety requirements; specific provisions have yet to be established in EU legislation. Moreover, regulations related to the right of intellectual properties as well as the absence of an appropriate framework for patent registration are issues delaying the process of products' industrial application. The utilization of high-quality nanomaterials is now growing and coming to the industrial arena rendering them as the next generation attractive resources with promising applications. Undoubtedly, the existing gap between basic research relating nanomaterials and their application in real life will be overcome in the coming decade.
\end{abstract}

Key words: Nanomaterials manufacturing, Large-scale synthesis methods, Industrial applications of nanomaterials, Carbon-based nanomaterials, Metallic nanoparticles, Metal CNTs hybrids, Metal oxides nanomaterials, Metal oxides/CNTs hybrids, Quantum dots, Quantum dots/CNTs hybrids

\section{Introduction}

At European level, the manufacturing industry is facing today a growing pressure derived from competitive economies. Especially in the high-technology area, there are already developed economies, such as China, which are threatening Europe's primacy [1]. To date, manufacturing sector consists of the $1 / 4$ of the EU's gross domestic product (GDP), while it offers millions of jobs, in times that unemployment is consistently growing. Despite the uprising economies, the EC industrial sector is dominating in international level, consisting of the flagship in areas such as automotive, and machinery.

In order for Europe to maintain this status, a new strategy needs to be implemented from cost-based competition to a new approach based on the creation of high added value products. Such a strategy should aim in more environmentalfriendly and high quality products. Additionally, new production methods have to be developed in order to combine greater production volumes with less energy and material consumption.

*e-mail: charitidis@chemeng.ntua.gr
Better synthetic methods to build and control particle morphology, in large-scale manufacturing, will be needed to broadly allow the penetration of nanomaterials (NMs) into industrial sector.

One of the most promising fields in the manufacturing section is NMs manufacturing. "Nanomanufacturing" is now a growing economy [2]. There are estimations that NMs' sales will reach the 14 billion Euros by 2015, while reliable estimations cannot be conducted beyond 2020. However, while NMs enter early in the value chain, they are often not visible in the final product. Thus, nanotechnology should be considered as a developing scientific field for the most of the industrial sectors with uncalculated profits by the end of this decade. Taking that into account, it is oxymoron the fact that nowadays there are relatively few companies in Europe working exclusively on NMs manufacturing. At a European level, nanomaterials' manufacturing does not reflect the global emphasis on carbon-based nanomaterials, such as fullerenes, carbon nanotubes (CNTs) and carbon nanofibres (CNFs). Most of the manufacturers that use nanomaterials in their production line do not use them in significant quantities. 
The scientific community turned their research efforts in the development of novel production methods of NMs in order to make their production more attractive to the industrial sector. Most of today's products involving fabricated nanostructures are produced using top down conventional technologies, while the large facilities, needed for large-scale production, have a huge environmental impact [3].

Unfortunately, most of the suggested methods fail either to apply to a large scale production, or in succeeding in preserving the produced NMs, with the desired properties. Another major issue that scientists deal with is the fact that these novel manufacturing processes should address to be equipped with in situ monitoring of the whole process in order to deliver high quality products. One possible solution is the online monitoring of the whole process which allows a constant feedback from the product quality, thus minimizing the chances of a product failure. Hence, it is critical for the scientific community as well as for the end-users, a strong cooperation to be developed in order these obstacles to be overcome.

In this sense, European Commission [4] has developed private-public partnerships in order to support research in the field of NMs manufacturing. In the frame of FP6 and FP7 projects, EC had invested $€ 240.000 .000$, while in the frame of HORIZON 2020, over 1 billion Euros will be invested from both the European Commission and manufacturing industries in order to develop and promote key enabling technologies. This investment will aid the European manufacturing industry and especially small and medium enterprises, to successfully correspond in this new competitive environment, through the development of novel manufacturing methods.

These newly developed NMs manufacturing methods, although still in research labs, are expected to provide with nanoparticles and nanostructures of high process throughput and low product costs. Rough estimations show that over $100 \mathrm{~kg} /$ day of products, ten times higher than today's volumes, will be synthesized by using innovative production methods. It is clear that such methods will dramatically decrease current nanomanufacturing obstacles, and lead in the creation of entirely new applications.

\section{Methods for large-scale synthesis of nanomaterials}

\subsection{Bottom-up approaches}

\subsubsection{Vapour phase techniques}

\subsubsection{Aerosol based processes}

A common method for industrial production of nanoparticles is the aerosol based processes $[5,6]$. An aerosol can be defined as a system of solid or liquid particles suspended in air or other gaseous environment. Particles can range from molecules up to $100 \mu \mathrm{m}$ in size. The use of aerosols was known many years before the basic science and engineering of them were understood. For example, pigments as carbon black particles and titania were used as reinforcements for car tires and for the production of paints and plastics, respectively. Another example is fumed silica and titania formed from respective tetra chlorides by flame pyrolysis. Also, optical fibres are manufactured by similar process [7].

Spraying is used either for drying wet materials or for applying coatings. When the precursor chemicals are sprayed onto a heated surface or into hot atmosphere, a precursor pyrolysis occurs and particles are formatted. An electro-spraying process in room temperature was developed at Oxford University for the production of semiconductors and metal nanoparticles [8]. Spray gun deposition technique was also applied for the deposition of catalysts precursors, such as iron chlorides (III), in order to achieve the growth of CNTs. Such methods of catalysts' deposition as film on various substrates are simple, cost effective and can be applied on large surfaces [9].

\subsubsection{Atomic or molecular condensation (gas condensation)}

The theory of gas-phase condensation process for synthesizing metal nanoparticles is certainly the oldest, having been first reported since 1930 [10]. The main parts of the gas condensation system are a vacuum chamber consisting of a heating element, the metal to be evaporized, powder collection equipment and a pumping system. A bulk material is heated to sufficiently high temperature (far above the melting point, but less than the boiling point) within a vacuum chamber in order to produce a stream of vaporized and atomised matter, which is directed to a chamber filled with either inert or reactive gas atmosphere. The pressure of the gas is high enough to promote particle formation, but low enough to permit spherical formation of the particles. Rapid cooling of the metal atoms, due to their collision with the gas molecules, lead to the nucleation and subsequently to the formation of nanoparticles. The introduction of oxygen as reactive gas into the system results in the production of metal nanoparticles. Attention should be given into the rapid oxidation, which may result in overheating and sintering of the particles. Gas evaporation typically leads to the production of materials with a broad particle size distribution and agglomerates due to the formation of particles being a purely random process $[8,11]$.

\subsubsection{Arc discharge generation}

Another means of vaporizing metals is the utilization of an electric arc as a source of energy. This technique is based on charging two electrodes made of the metal to be vaporized in the presence of an inert gas. A large current is applied until the breakdown voltage is reached. The arc created across the two electrodes leads to the vaporization of a small amount of metal of one electrode to another. This method produces very small amounts of metal nanoparticles, but is characterized by relative reproducibility. Metal-oxides or other compounds can be produced by using oxygen or another reactive gas [12]. Even though the arc discharge is a well-known method, the process control of the arc's extremely high temperature leading to high evaporation rates is of significant importance for industrial processing. Moreover, high concentrations of the vaporized metal in the carrier gas may produce large particles [11].

A European project named BUONAPART-E (Better Upscaling and Optimization of Nanoparticle and Nanostructure 


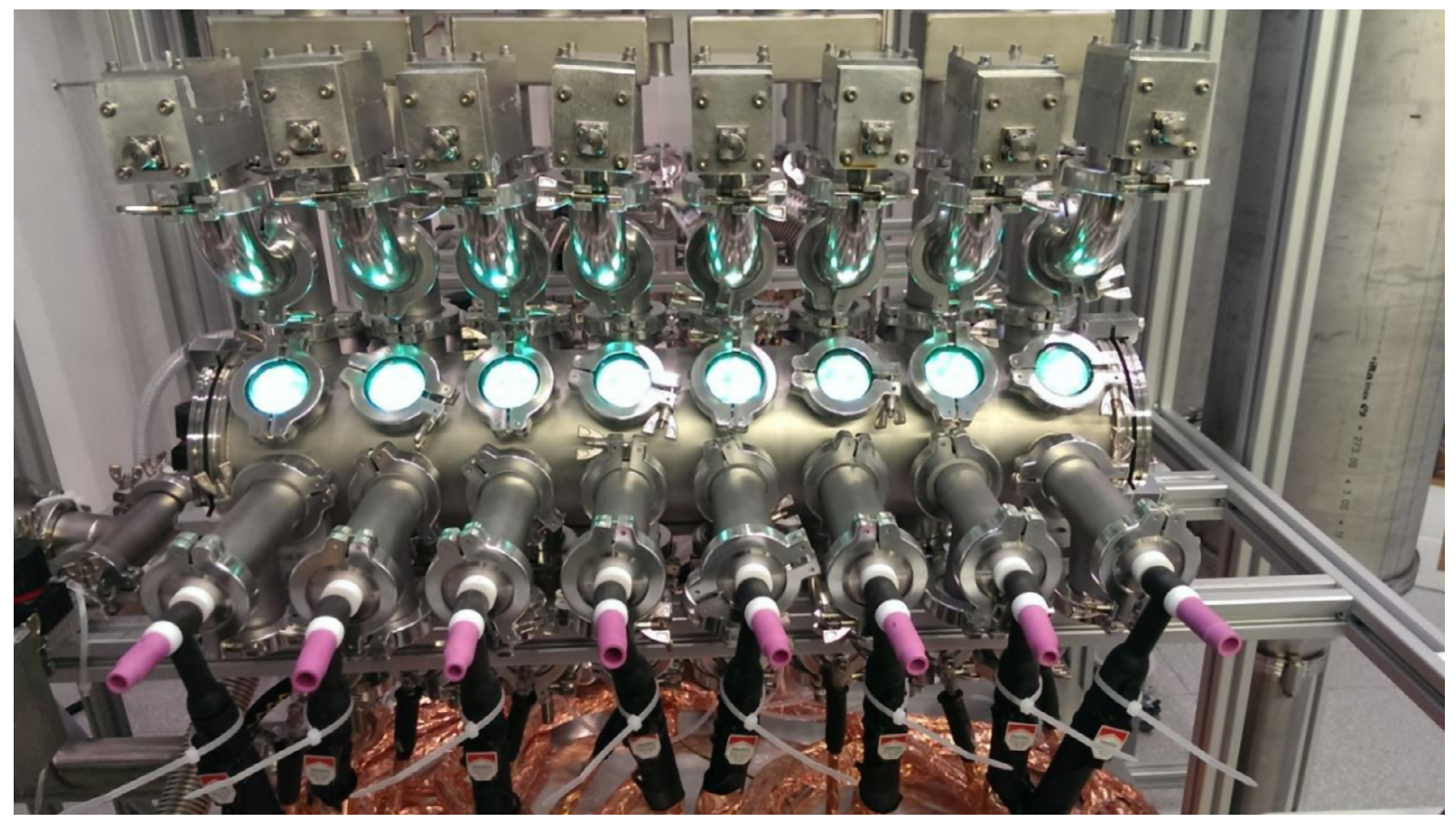

Figure 1. Multiple optimized single units of BUONAPART-E's project for large scale production of metal nanoparticles by using electrical discharge methods.

Production by Means of Electrical Discharges) [13] is currently running and aims at the development of an optimized single unit (OSU), which is depicted in Figure 1. The latter is the basic evaporation unit, for large scale production of metal nanoparticles by using electrical discharge methods. The process is simple, versatile and reliable and the production rate ranges between 0.1 and $10 \mathrm{~g} / \mathrm{h}$, an increase by a factor of 10 to 100 beyond the current state-of-the-art for the single unit. The basic unit is a pair of electrodes and a large number of these pairs can be placed in a single housing, resulting in the demonstration of multiple units of the OSU in parallel, in a closed-loop carrier gas recycling system, in a production facility yielding $1 \mathrm{~kg} /$ day. The challenge of this project is to show that the product quality from multiple parallel OSUs and a single unit are identical. The size of the primary particles is controlled by the carrier gas composition and the applied electric current. Nitrogen is the most economic carrier gas, leaving electric current as the only process parameter. A higher electric current results in the production of bigger particles and thereby to an increased production rate. The parallelization of many electrode pairs can optimize both production rate and particle size $<100 \mathrm{~nm}$. Current results of the project include that the production rate of about $0.6 \mathrm{~kg} /$ day of the multiple OSU containing 8 OSUs is approximately 8 times the production rate of the OSU; and the specific electricity consumption is in the same range for the multiple OSU as it is for the OSU. To conclude, this is a very important result as it proves that the scaling-up by multiplying the number of OSU in one housing is working for large scale production of metal nanoparticles [14, 15].

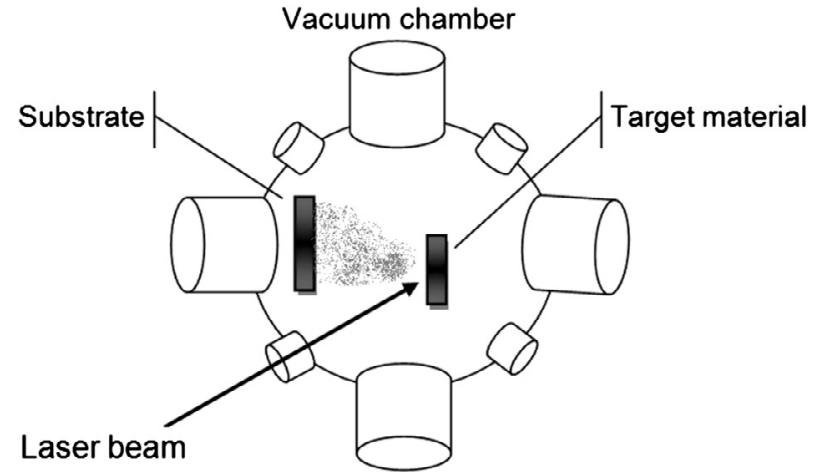

Figure 2. Schematic representation of laser ablation process consisting of vacuum chamber, laser beam, target material and substrate to be coated [18].

\subsubsection{Laser ablation process}

Laser ablation technique consists of two important elements: the high-power laser beam with the optical focusing system and the feeding device of the metal-target (Figure 2). The laser beam is focused at the surface of the target and a supersonic jet of evaporated material (known as plume) is ejected perpendicular to the target surface, expanding into the gas space above the target. The particles formed are transported with the carrier gas to the product collector. The use of metals and metal oxides as precursors is the main advantage of this method as well as the production of high crystalline materials. The concentration of particles and their size distribution 


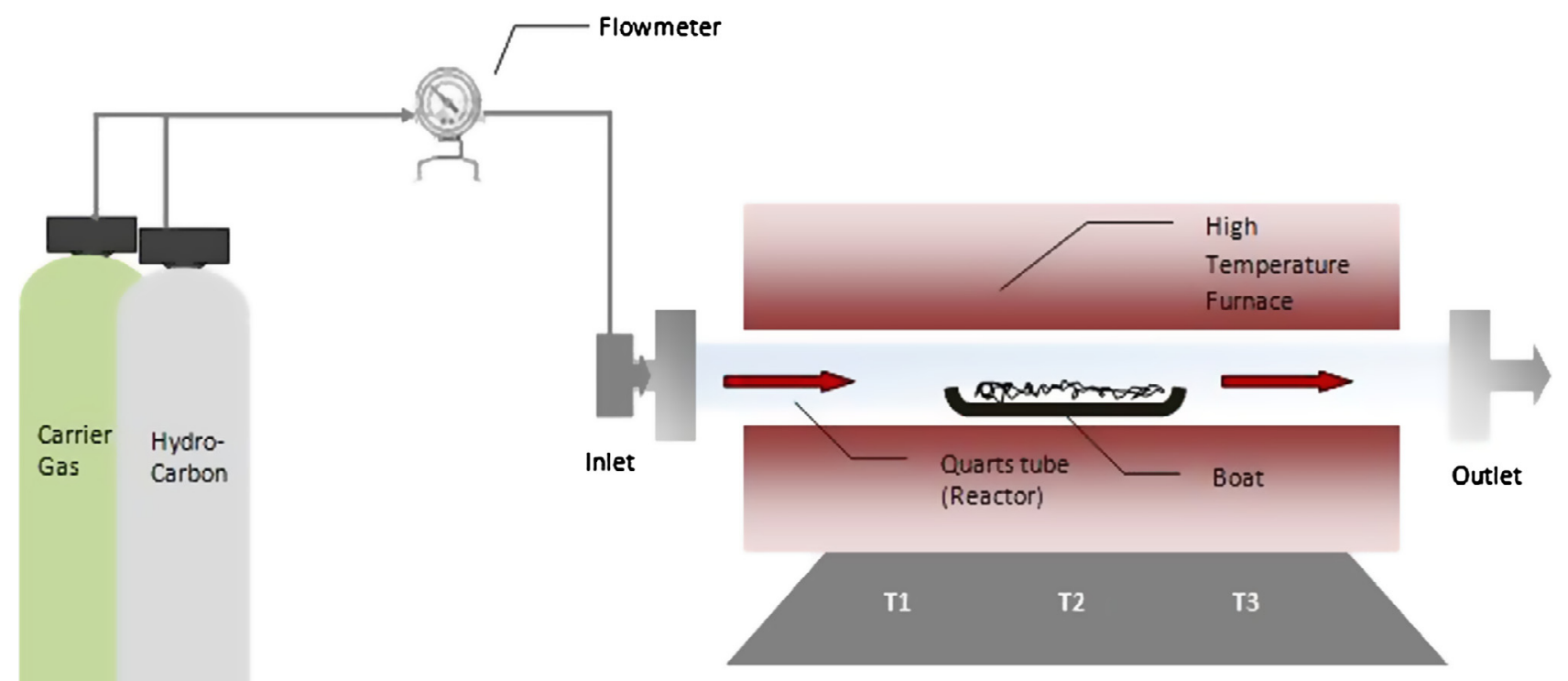

Figure 3. Laboratory scale CVD system.

depends on the experimental medium in the ablation chamber (ambient air, argon and water), the target material and the laser operating parameters (wavelength, pulse duration, energy, repetition time and beam scanning speed). Experimental estimations showed that the mass of generated nanoparticles in ambient air was up to 100 times higher than in water and that in argon gas was up to 100 times higher than in ambient air. For example, using nanosecond-laser the generation of Nickel particle concentration was estimated up to $1.2 \times 10^{5} \mathrm{~cm}^{-3}$ in ambient air and $1.4 \times 10^{6} \mathrm{~cm}^{-3}$ in argon gas flow [16]. However, the high concentration of evaporated material in the plume can lead to the formation of agglomerates. This process is not often applied, especially in large-scale, due to its low yield and high operation cost $[11,17]$.

\subsubsection{Plasma process}

Plasma processes can be divided into two categories, microwave plasma process and plasma spray synthesis. In the microwave plasma process, particles are originating in the plasma zone, carrying electric charges. As a result, agglomeration and coagulation can be reduced due to the benefits of the charged particles $[19,20]$. Because the reactants are ionized and dissociated, lower reaction temperatures can be achieved, than chemical vapor deposition, but the electrical charges of the particles remain. Advantages of the method are the high production rates, the narrow particle size distribution and the ability of producing unagglomerated particles [21]. Plasma spray synthesis is a method that can be used even in the open atmosphere for the production of nanoparticles. Because the flow velocity of the nanoparticles is extremely high, the collection of the produced nanoparticles is demanding. Advantages of the method are its simplicity, the low cost and the massproduction that can be achieved. Requirements for safe and efficient particle collection restrict the application of the method [8].

\subsubsection{Chemical vapor deposition}

Chemical vapor deposition (CVD) is referred to activating chemical reactions between a substrate surface and a gaseous precursor in order to a thin solid film be deposited onto the substrate [22]. Activation can be achieved either with increased temperatures (Thermal CVD) or with plasma (PECVD: Plasma Enhanced Chemical Vapour Deposition); decreasing significantly the process temperature compared to the thermal CVD process. This technique is a widely used materials-processing technology due to its low set-up cost, high production yield, and ease of scale-up [23]. Chemical vapor deposition has been developed as a novel manufacturing process in many industrial sectors such as semiconductor and ceramic industry [24]. A typical industrial CVD system includes gas delivery system, reaction chamber or reactor, loading/unloading system (transport of substrates), energy system, vacuum system, process automatic control system, and exhaust gas treatment system (e.g. $\mathrm{NaOH}$ and liquid $\mathrm{N}_{2}$ traps before by-products being released into the atmosphere). The gases are delivered into a reaction chamber operated at a suitably determined high temperature (500$1200{ }^{\circ} \mathrm{C}$ ). Also, inert gases, such as argon and nitrogen, are usually used as carrier gases. The gases pass through the reactor coming into contact with the heated substrate; they react and form a solid layer deposited onto the substrate's surface. The temperature and pressure system are the critical operation parameters of this process [23]. A laboratory scale CVD system is depicted in Figure 3.

CVD is widely used for the production of CNTs and is the only promising method for scaling-up compared to arc discharge and laser assisted methods [8, 25]. Recently, a swirled floating catalytic chemical vapour deposition (SFCCVD) reactor was developed with the scope of up-scaling the production capacity using a vertical reactor inside a furnace and cyclones for collecting the final product [26]. 


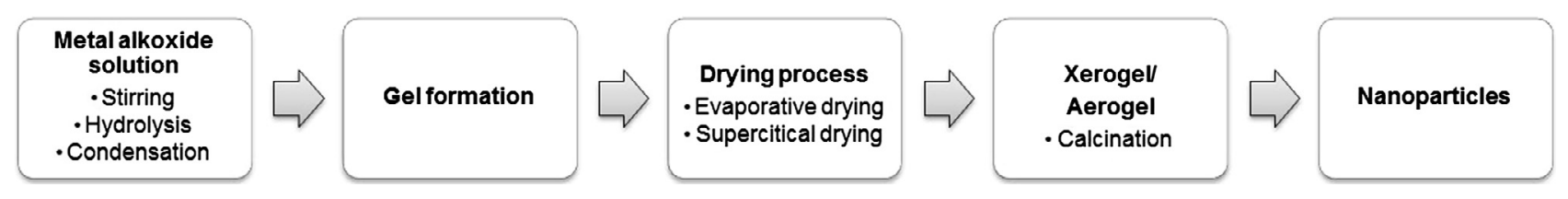

Figure 4. Main stages of sol-gel method [17].

As mentioned, CVD is a powerful method with many advantages ranging from uniform thickness of coatings, flexibility of using a wide range of chemical precursors $(70 \%$ of elements in the periodic table have been deposited), no requirement of using ultra-high vacuum environment up to control of surface morphology and orientation of manufactured products. However, CVD process invokes safety issues and health hazards derived from the production of by-products. Also, despite being a flexible method, CVD requires numerous experiments for standardizing the appropriate growth parameters [24].

\subsubsection{Liquid phase techniques}

\subsubsection{Sol-gel}

Sol-gel method is a long established industrial process for generating colloidal nanoparticles from liquid phase. It has been further developed in the last years for the production of advanced nanomaterials and coatings [27, 28]. Sol-gel process is a chemical method which is based on hydrolysis or condensation reactions (Figure 4). With the correct amount of reactants, nanosized particles precipitate. Sol-gel techniques show many advantages like low temperatures during processing, versatility and easy shaping and embedding. Common precursors which are used for the production of oxides are alkoxides, due to their availability and to the high liability of the M-OR bond allowing facile tailoring in situ during processing. This method lucks the risk for nanoparticle release after the drying of the solution [8].

\subsubsection{Solvothermal method}

Solvothermal method is appropriate for the preparation for both crystalline oxide- and non-oxide materials. Crystalline solids, including silicate materials with high porosity like zeolites [29] and oxide or non-oxide nanoparticles [30] can be produced by this method. Examples from non-oxide nanomaterials that can be produced by solvothermal method and have several applications are semiconductors (e.g. GaN) [31], carbon nanotubes, diamonds and carbides [32], chalcogenides, nitrides, phosphides or borides. The main advantage of the method is that problems like solvents' toxicity, inability of dissolving salts and expense, can be overtaken. In the solvothermal method, solvents are employed well above their boiling point in enclosed vessels. By this way, high autogenous pressures can be supported. Organic solvents can be used to disperse nonoxide nanocrystallites and to stabilize metastable phases. When the used solvent is water, the method is called hydrothermal. Many times the method includes extra processes as hydrolysis, oxidation and thermolysis [33]. The hydrothermal synthesis is suitable for the production of fine powders and oxides.

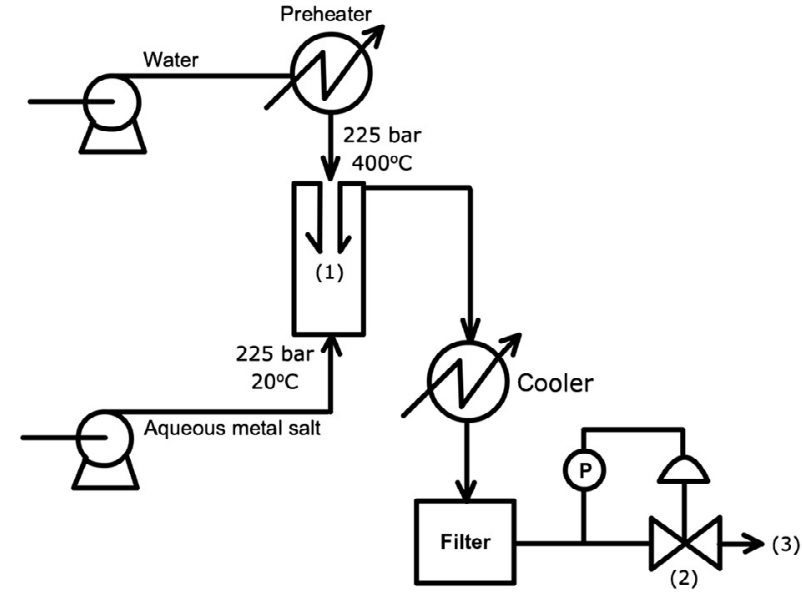

Figure 5. SHYMAN's continuous hydrothermal reactor system showing inlets, mixing zone and formulation stages.

The operation temperatures are usually below $100{ }^{\circ} \mathrm{C}$ and the pressure exceeds the ambient pressure.

Hydrothermal synthesis is an enabling and underpinning technology that is ready to prove itself at industrial scale as a result of recent breakthroughs in reactor design, which suggest that it could now be scaled over 100 tons per annum. Continuous hydrothermal synthesis produces nanoparticulate material by mixing superheated/supercritical water with a solution of a metal salt. That is, rather than slowly heating the entire contents of a batch vessel, the two different fluids are continuously mixed together. When water is heated towards its critical point $\left(374{ }^{\circ} \mathrm{C}, 218 \mathrm{~atm}\right)$ the ionic product $\left[\mathrm{H}^{+}\right]\left[\mathrm{OH}^{-}\right]$increases and the superheated fluid is technically supercritical, rather than near-critical.

Another project named SHYMAN (Sustainable Hydrothermal Manufacturing of Nanomaterials) [34], funded by European Commission, focuses its main goal on finding the optimum reactor design that can manufacture 100 tons/annum (dry weight equivalent) of formulated nanomaterials. The current system's yield is 1 ton/annum with some early indications that 10 tons/annum can be achieved with the same reactor using faster flow rates. The system will be capable of sustaining operation at a range of superheated conditions from sub-critical (starting at $100{ }^{\circ} \mathrm{C}$ and 10 bar) to near critical and supercritical conditions $\left(>374{ }^{\circ} \mathrm{C}\right.$ and $\left.>218 \mathrm{~atm}\right)$. In Figure 5 the SHYMAN's continuous hydrothermal reactor system showing inlets, mixing zone and formulation stages is presented. Specifically, the superheated fluid passes down an inner nozzle pipe (A) against an up flow of cold metal salt (B). Nanoparticles form at the interface of the two fluids and the buoyancy of the heated flow causes the nanoparticle slurry to be carried 
upwards (downstream). The nanomaterials themselves can then be formulated (C) before cooling (D) and collection [35].

\subsubsection{Sonochemical method}

Sonochemistry is the research area in which molecules undergo chemical reaction due to the application of powerful ultrasound radiation [36]. The driving force responsible for the sonochemical process is acoustic cavitation, which includes the formation, growth and collapse of bubbles in an ultrasonically irradiated liquid. Even though, cavitation is considered to be avoided in the construction of reactors (erosion damage), acoustic cavitation is the key to sonochemical processing due to its ability to control and limit its effects to the reaction and not the reactor [37]. This method has been extensively used to produce nanosized materials with unusual properties, since the unique conditions (very high temperatures $(5000 \mathrm{~K})$, pressures $(>20 \mathrm{MPa})$ and cooling rates $\left.\left(>10^{9} \mathrm{~K} \mathrm{~s}^{-1}\right)\right)$ facilitate the formation of smaller particles and different shapes of products compared to other methods [38]. The main advantage in conducting sonochemical experiments is that it is very inexpensive.

\subsection{Top-down approaches}

\subsubsection{Solid phase techniques}

\subsubsection{Mechanical attrition (milling/mechanochemical processing)}

Mechanical attrition (MA) is a method that has been developed since 1970, as an industrial process for producing new alloys and phase mixtures from powder particles. This method can overcome the quantity limitations for nanocrystalline preparation, so nanocrystalline powders can be produced in large scale. Moreover, it offers many perspectives in preparing a different number of structures in nanostructured powders, like crystalline/crystalline or crystalline/amorphous and atomic bonding like metal/metal, metal/semiconductor, metal/ceramic, etc. An important advantage is that mechanical milling process can work at low temperatures, so the newly formed grains can grow very slowly [8]. By this method it is possible to prepare advanced materials with particular grain or interface-boundary design. Because in many cases it is difficult to distinguish a glassy structure by a nano-crystalline structure, research is oriented to nanocrystalline nanomaterials, in which grain or interphase boundaries between the nanophase domains exist [39].

Two different techniques have been developed for the production of nanopowders using mechanical milling. The first one is milling a single phase powder by controlling the balance point between fracturing and cold welding. By this way, particles larger than $100 \mathrm{~nm}$ cannot be excessively cold welded [8]. As a result, a reduction of the average grain size from $50-100 \mu \mathrm{m}$ up to $2-20 \mathrm{~nm}$ is obtained. The reason that this reduction of the order of $10^{3}-10^{4}$ for the average grain size occurs, is the creation and self-organization of large-angle grain boundaries between the powder particles. The mechanism of microstructure formation is very different from the other synthesis methods, but the final microstructure is very similar.
A severe plastic deformation occurs due to mechanical attrition, so a continuous refinement of the internal structure of the powder particles to nanometer scales is accomplished [39]. Temperature rises during the process over $100{ }^{\circ} \mathrm{C}-200{ }^{\circ} \mathrm{C}[40]$.

While mechanical milling is very sensitive to contamination, atmospheric control can be used for chemical reactions between the environment and the milled powders [39]. This has led to the development of a novel, cost effective method of producing a variety of nanopowders, Mechanochemical Processing (MCP), which consists the second method of mechanical attrition. In MCP a conventional ball mill can be used as a low temperature chemical reactor. The ball mill increases the reaction kinetics in the reacting powder mixture as a result of the intimate mixing and refinement of the grain structure to the nanometer scale. The reaction occurs during the actual milling. For this reason, a proper reactive gas, like $\mathrm{O}_{2}, \mathrm{~N}_{2}$, atmospheric air, etc. and a suitable precursor are chosen [8]. A variety of metals such as Ti, Fe, V, $\mathrm{Zr}, \mathrm{W}, \mathrm{Hf}, \mathrm{Ta}$ and Mo demonstrate the potential of reactive milling [41-43]; they can be transformed to nanocrystallines of metal nitrides and oxides. Concerning the wet milling, an organic fluid can also be used. Metal powder can be transformed to nanocrystalline metal-ceramic composite by this method [39]. The resulting product phase is formed as individual single nanometer sized grains, in a by-product matrix. For this reason, it is necessary to confirm that the reaction has finished, so temperature heat treatment often follows the process.

The reduction of the process cost and the industrialization of products can be achieved by using a variety of precursors, like oxides, carbonates, sulphates, chlorides, fluorides, hydroxides and others [8]. Different ball mills have been developed for mechanical attrition, such as tumbler mills, attrition, shaker mills, vibratory mills, planetary mills, etc. [44]. The method includes shaking or violent agitation. The material powder is placed in a sealed container with coated balls by hardened steel or tungsten carbide. The mass ratio for the ball to the powder shall be 5:10, with a typical particle diameter $50 \mu \mathrm{m}$ for the powder. Kinetic energy of balls is a function of their mass and velocity, as a result, steel or tungsten, which are high density materials, are preferable as means of milling [39].

\subsection{Hybrid approach - nanolithography}

Nanolithographic techniques (Figure 6) are appropriate for the fabrication of 1D nanostructures [45], nanocatalysts [46], semiconductors, etc. They include electron-beam or focusedion-beam writing [47, 48], proximal probe patterning [49, 50], X-ray lithography $[51,52]$ and many other methods. Nanolithography also includes dry or wet etching. In the context of fabrication of nanostructures the definition of lithography should be referred not only as a top-down, but also as a bottom-up route. By nanolithography, nanostructures or their arrays can be synthesized, by a directed growth process or by a constrained growth from one to few nanometers. The advantage of these methods is that large quantities of 1D nanostructures can be prepared, using a wide variety of materials, which are available [33]. 


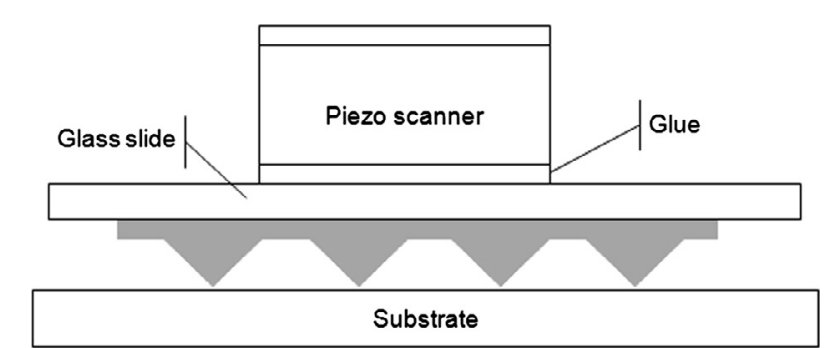

Figure 6. Scheme of the polymer tip array in patterning instrument [53].

\subsubsection{Template fabrication}

One of the most popular and maybe cheapest methods of nanolithography is the template fabrication, which uses nanometer size templates. This method is suitable for the growth of nanowires, by electrodeposition, sol-gel or by vapor-phase. Nanowires can be decoupled with the templates and can be also independently controlled. First of all, templates of ordered nanopores have to be made. Secondly, the pores should be filled with the chosen materials, using one of the methods referred before.

Electrodeposition of metals inside the nanopores is performed in acidic or basic baths that contain metal salts. A three-terminal potentiostat is used. The metal is deposited on the cathode (working electrode) and for this reason, one end of the porous membrane is metallized with $\mathrm{Ti}$ and $\mathrm{Au}$ or $\mathrm{Ag}$ by sputtering or evaporation. The anode (counter electrode) is normally made of graphite or Pt and the reference electrode can be calomel or $\mathrm{Ag} / \mathrm{AgCl}$. The deposition conditions (DC or pulsed) affect the polycrystallinity of the nanowires [33].

Sol-gel method can be used as a low temperature synthesis route for complex oxides [54], like functional oxide nanowires. A postdeposition high temperature annealing $\left(>500-600{ }^{\circ} \mathrm{C}\right)$ is needed to form the required stoichiometric phase. And for this reason, alumina templates are used. After the required sol is prepared, the template is put into the sol for a specific time period. The membrane is then taken out from the sol, gets dried and annealed at higher temperature before the required phase is formed.

Chemical and physical vapor deposition can be used for the growth of semiconductor nanotubes, including ordered arrays of CNTs. CVD process takes place in a three-zone furnace with deposition temperatures varying from 500 to $1000{ }^{\circ} \mathrm{C}$. As the temperature increases, graphitic content varies, with progressive increase in metallic appearance, decrease in resistance and enhanced tube wall structure. CVD techniques, particularly plasma assisted CVD, show many perspectives to grow aligned nanotubes of complex semiconductor or oxides in alumina templates and in future this technique will certainly find more applications [33].

\subsubsection{Scanning probe microscopy (SPM)}

SPM-based nanolithography is an established procedure for creating patterns at nanometer level. Metallic and semiconducting surfaces have been patterned using this route.

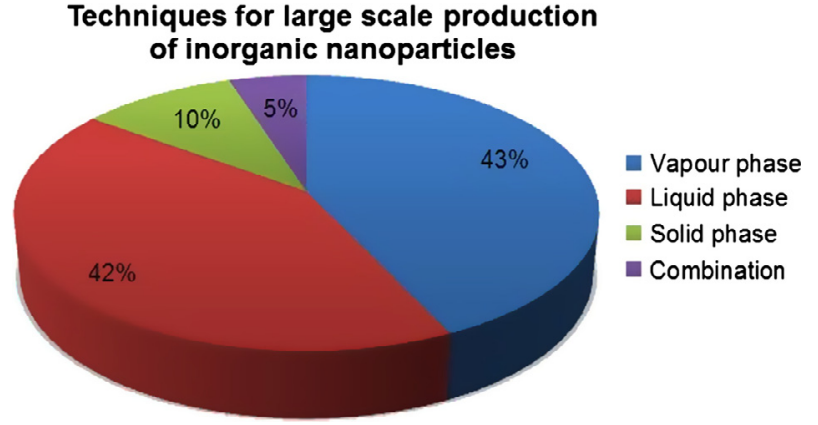

Figure 7. Vapour and liquid phase techniques are the leaders for large scale production of inorganic nanoparticles [59] http://nanoparticles.org/standards/.

These patterns can be transferred onto an underlying substrate, in the same way with the other lithography masks in optical or $\mathrm{e}^{-}$beam lithography. Nanoelectronic devices can be fabricated by this method. The main advantage of the SPM-based lithography is that the same SPM can be used for writing the pattern and for imaging after the writing process.

Two ways exist for creating reproducible patterns in nanometer scale; "chemical route" which is dip-pen lithography (DPN) and SPM, based on anodic oxidation. The central role in both methods plays the water meniscus between the tip and the substrate.

For the anodic oxidation, meniscus acts like an electrochemical cell. The writing operation needs normally ambient air with moisture over than $50 \% \mathrm{RH}$. The meniscus is formed by the atmospheric moisture capillary which condenses on the surface of the substrate. The moisture can be described as a "nano-reaction vessel" for anodic oxidation. A bias is applied between the tip and the substrate. For oxidation, the substrate is at a positive bias with respect to the tip. Its magnitude is the second important parameter. The applied field accelerates the $\mathrm{OH}^{-}$ions to the substrate, which is oxidized, according to the Mott mechanism [55]. The oxidation process stops when the field falls below a critical value $\left(107 \mathrm{~V} \mathrm{~cm}^{-1}\right)$, as it decreases. So, the process can be described as self-limiting. The width and the height of the oxide grown depend on the applied bias. The radius of curvature of the tip is also important, which is made by well-defined and controlled micromachining lithography, in reproducible sizes, shapes and aspect ratios. As a result, reproducible lithography of given resolutions can be performed, which is a big advantage [33].

In DPN the water meniscus acts as a medium for molecular transport. The technique depends on the ability of the deposited molecule to be transported in a controlled way from the tip to the substrate. The molecule is called "ink" and should interact with the substrate for a formation of a chemical bond, to create a stable structure [56]. An interesting alteration of DPN is to use the meniscus as an electrochemical cell, by applying a bias between the two, similar to the anodic oxidation described before. This electrochemical DPN technique can be used to fabricate metal and semiconductor nanostructures directly [57]. DPN can also be used for the creation of nanostructures on a surface for directed assembly of nanoparticles [58] (Figure 7). 


\section{Carbon-based materials}

\subsection{Fullerenes}

The most widely studied fullerene is the $\mathrm{C}_{60}$ molecule (also known as Buckminsterfullerene) with a spherical molecular structure of $\sim 1 \mathrm{~nm}$ in diameter, consisting of 20 hexagonal and 12 pentagonal rings $[60,61]$. There are also fullerenes with higher mass such as $\mathrm{C}_{70}, \mathrm{C}_{76}, \mathrm{C}_{78}$ and $\mathrm{C}_{80}$ with different geometric structures [62]. The great scientific interest in fullerene $\mathrm{C}_{60}$ can be explained by the following reasons: (i) it can be abundantly produced in the carbon soot from carbon evaporation by arc discharge, (ii) it has high symmetry (icosahedral $\mathrm{I}_{\mathrm{h}}$ with all 60 carbons chemically equivalent), (iii) it is less expensive, (iv) it is relatively inert under mild conditions and (v) it is less toxic [63]. Generally, fullerenes possess unique properties such as super conductivity and anti-oxygen activity [61].

The most common laboratory-based methods of synthesis for fullerenes [64] are the following two methods: the arc discharge of graphite electrodes in 200 Torr in the presence of He (Krätschmer-Huffman method), leading to yields of up to $70 \%$ of $\mathrm{C}_{60}$ and $15 \%$ of $\mathrm{C}_{70}[63,65]$ and the gas combustion method [66] where a continuous low flow of hydrocarbon fuel (e.g. benzene, acetylene) is burned at low pressure in the presence of oxygen. The latter method has the advantage of producing large clusters of fullerenes (that are only produced in low yield by the arc-discharge method), whose size distribution can be easily controlled by varying the parameters of combustion. Moreover, the doping of clusters is readily achieved by introducing dopants in the combustion mixture [67]. Those methods have been successfully adapted to the large-scale production of fullerenes [68, 69].

Particularly the gas combustion method enabled the production of fullerenes in tonnes-per-year [70]. Furthermore, laser vaporization is also employed for fullerene production, using an apparatus of a pulsed Nd:YAG laser as the laser source, operating at $532 \mathrm{~nm}$ and $250 \mathrm{~mJ}$ of power and the graphite target keeping it at $1200{ }^{\circ} \mathrm{C}$ in a furnace [71].

Fullerene/fullerene clusters produced with the aforementioned methods are in the form of a crude mixture containing $\mathrm{C}_{60}$ and other $\mathrm{C}_{n}(n>60)$ as well as conventional hydrocarbon species. For their isolation from the crude soot, purification methods are applied such as Soxhlet extraction with toluene (in which fullerenes are soluble) and with ethers (e.g. diethyl ether) to remove the soluble impurities of hydrocarbons and accordingly isolation of pure $\mathrm{C}_{60}$ and other individual fullerenes employing chromatographic methods [67]. Liquid Chromatography (LC) has been used since 1990 for the fullerenes' separation, isolation and purification. This method is also used to control reactions of fullerenes such as nucleophilic additions, cycloadditions, hydrogenations and oxidations with electrophiles [72]. Typically in chromatographic methods two phases are used, a mobile phase and a stationary phase. Here, the mobile phase is an aromatic solvent with high fullerene solubility, sometimes to which the addition of a non-aromatic solvent with comparatively low fullerene solubility enhances the efficiency of fullerene separation. As a stationary phase different sorbents can be used with relatively high affinity for the fullerenes [73]. A variety of stationary phases have been used so far, such as normal and reversed or charge-transfer stationary phases, using LC or HPLC (high performance liquid chromatography) and moreover size exclusion stationary phases in gel permeation chromatography, but most of them are limited to gram scale separations. Therefore, the research now focuses on finding more selective stationary phases mainly based on charge-transfer Chromatography. The development of improved chromatographic methods would provide higher efficacy and better resolution concerning fullerene separation at both analytical and preparative scales, and at the lowest cost [72]. One such economically viable solution [74] is the use of a cheap stationary phase of celite (a naturally occurring, soft, chalk-like sedimentary rock) in combination with activated carbon and silica gel.

The first commercial usage of fullerenes reported in 2003 in 10-pin bowling balls as a coating of resin containing fullerenes. Such coating prevents ball from wearing and enhances its controllability [69]. The authors count today 24 registered fullerene suppliers, 19 of which are manufacturers mainly based in the United States and the others in Europe and Asia [75]. However, a wide range of fullerene $\mathrm{C}_{60}$ prices still exist beginning from US \$20 per gram and extending to US \$180 per gram for 99\% purity. Their high cost and small unit sales sizes compared to other nanoparticles, discourage their widespread usage, although a large array of potential applications has been identified, including optics [76], electronics/IT (information technology) devices [77, 78], diagnostics, pharmaceuticals, environmental and energy industries [69].

\subsection{Carbon nanotube and carbon nanofibres}

Both CNTs and CNFs are graphitic filaments with diameters ranging from 0.4 to $500 \mathrm{~nm}$ and are available in varying lengths, up to several hundred micrometers, depending on the production method [79]. SWCNTs are composed of a single cylindrical sheet of graphene and MWCNTs several concentric, coaxical rolled up graphene sheets [80]. Specifically, the CNT diameters are typically 0.4 to $2 \mathrm{~nm}$ and up to $200 \mathrm{~nm}$ for singlewalled carbon nanotubes (SWCNTs) and multi-walled carbon nanotubes MWCNTs), respectively [81]. CNFs are formed by graphene nanocones or "cups", sometimes are referred to as "stacked-cup carbon nanotubes" with diameters ranging from 70 to $200 \mathrm{~nm}$ depending upon the carbon nanofibre type [82].

After the discovery of CNTs by Iijima in 1991 [83], CNTs and CNFs have attracted the scientific interest owing to their excellent physicochemical, electrical and mechanical properties. SWCNTs can be metallic or semiconducting depending on the orientation of graphitic filaments; individual SWCNTs can have a thermal conductivity of $3500 \mathrm{~W} \mathrm{~m}^{-1} \mathrm{~K}^{-1}$ at room temperature, exceeding the thermal conductivity of diamond [84]. Their applications in the area of polymer composites as fillers, microelectronics, energy storage and sensors have been widely reported [85]. CNTs and CNFs are usually obtained by CVD method from the decomposition of gaseous hydrocarbon over transition metal-catalyst particles [22]. Other methods such as flame synthesis, arc discharge and laser ablation are too energy intensive, expensive and result in less yield compared 
Table 1. Companies producing SWCNTs and MWCNTs [23, 85].

\begin{tabular}{|c|c|c|}
\hline SWCNTS company & Production capacity $(\mathrm{g} / \mathrm{h})$ & Materials \\
\hline Carbon Nanotechnologies Inc. (USA) & 65 & Carbon monoxide iron pentacarbonyl \\
\hline Toray Industries Inc. (Japan) & 15 & Alcohol \\
\hline AIST (Japan) & 10 & $\begin{array}{l}\text { Ethylene, Fe thin film }(1.5 \mathrm{~nm}) \text { supported } \\
\text { on an AlOx layer }(30 \mathrm{~nm})\end{array}$ \\
\hline$M W C N T s$ company & Production capacity $(\mathrm{kg} / \mathrm{h})$ & Materials \\
\hline Showa Denko KK (Japan) & 16 & Benzene, metal catalyst \\
\hline Heperion Catalysis International, Inc. (USA) & 8 & $\mathrm{~N} / \mathrm{A}$ \\
\hline Nano Carbon Technologies Co. Ltd. (Japan) & 5 & $\mathrm{~N} / \mathrm{A}$ \\
\hline Sun Nanotech Co. Ltd. (China) & 0.6 & N/A \\
\hline $\begin{array}{l}\text { Shenzhen Nano-Technologies Port } \\
\text { Co. Ltd. (China) }\end{array}$ & 5 & \\
\hline Meijo Nano Carbon Co. Ltd. (Japan) & 1 & Camphor zeolite powder \\
\hline
\end{tabular}

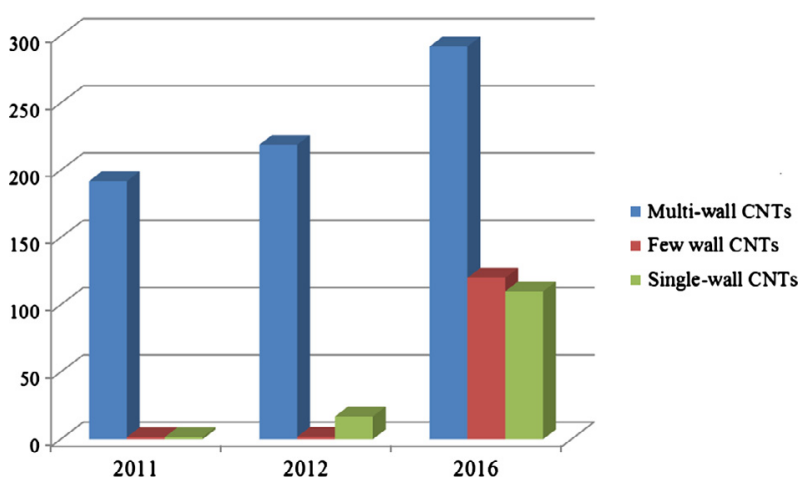

Figure 8. Global market for CNTs grades based on committed production, 2011-2016 [90].

to CVD [86]. The CVD method is the most dominant technique for mass production of CNTs due to its easy scaling-up. However, the most common problem is focused on their purity, which decreases with increased yield. Their synthesis routes at laboratory scale can be easily monitored, in order to tailor their final properties [23]. Industrial equipment is more sophisticated and complex in design, as compared to laboratory CVD equipment due to its accommodation of large-scale deposition [22].

The production of both nanomaterials in large scale can result in difficulties as the same technique is applied in large reaction vessels decreasing their purity and broadening diameter distribution [87-89]. Taking into account their increasing demand, a more refined method permitting the control of parameters and reduction of contaminations is needed to be established in order their mass production to be further developed with less defects.

CNT-related commercial activity has been reported more substantially during the past decade. The CNT production capacity as well as annual number of journal publications and patents follows an increased growth. Globally, the yearly CNT production capacity is estimated to be $\sim 300$ tons MWCNTs and $\sim 7$ tons SWCNTs, while their anticipated demand would exceed 1000 tons/year in the near future. Their commercially available price can reach $\sim \$ 1 / \mathrm{g}$ and $\sim \$ 500 / \mathrm{g}$ for
MWCNTs and SWCNTs, respectively rendering CNT-based products more expensive up to 10 times than prevalent ones. SWCNT synthesis by CVD requires much tighter process control compared to MWCNTs', rendering their prices orders of magnitude higher than of MWCNTs'. As mentioned before, SWCNTs have metallic or semiconducting behavior and their price depend on this. CoMoCat ${ }^{\circledR}$ SWCNTs cost up to $€ 500$ for $1 \mathrm{~g}$ with $98 \%$ of semiconducting SWCNTs. For this reason, the electronic industry has lost interest for them because it is not possible to completely control their chirality and it was too difficult to handle them at low costs. Indeed it is not the more costeffective production of SWCNT that it is the real problem; the real problem is focused on controlling their electronic behaviour. Therefore, MWCNTs, being metallic, are preferred for applications where diameter is not a crucial parameter; the development of more cost-effective SWCNT production techniques is required in order to obtain industrial entity [85]. Aixtron company is leader on CNTs market and has developed an industrial machinery for CNTs growth. Figure 8 shows the Global market for CNTs grades based on committed production, 2011-2016.

Globally, there are many companies producing CNFs. One of the most known suppliers is Pyrograf Products, Inc. (USA). Their price depends on their final application from $\$ 85 / \mathrm{lb}$ (electrical applications) to $\$ 170 / \mathrm{lb}$ (thermal applications). There are also other companies such as: Carbon NT\&F 21, Catalytic Materials LLC (\$40-50/g), Catalyx Nanotech, Inc., Electrovac AG, Espin Technologies, Inc., Graphenano, Nanostructured \& Amorphous Materials Nanofibres Products $(\$ 10-20 / \mathrm{g})$, and $\mathrm{CoMoCat}^{\circledR}$ (Table 1).

Summarizing, the industrial production of carbon-based materials depends on many parameters such as precursor, catalyst, catalyst support, and, growth mechanism affecting the final material's structure and properties. Minor changes in these parameters lead in products with critically different properties. The improvement of their production includes future activities related to the selection of the suitable catalyst diameter, which directly affects the diameter distribution for both produced SWCNTs and MWCNTs [91]. The selection of catalyst (e.g. metals) is directly associated with the final physical, chemical, electronic, optical and magnetic properties. Therefore, the 
advantage to understand the correlation between the type of the metal used and the final properties would result in the production of carbon-based materials with tailored properties. Also, the development of a suitable method to separate metallic and semiconducting CNTs and reduction of catalyst impurities are other challenges [92]. Recent studies on synthesis of CNTs without metal support and oxygen assisted is breakthrough; future studies should focus on scaling-up this method resulting in the production of CNTs with dramatically reduced impurities $[93,94]$. Finally, it would be of great importance to explain the fundamental growth mechanisms, which would benefit researchers to understand the complicated interdependency among structural parameters. The detailed understanding of the processes and in situ control would constitute a guide for the successful mass production of CNTs with tailored properties.

Carbon nanotube-nanocrystal hetero-structures [95] have evolved through the years gaining serious interest in recent years, due to their impact on a wide range of areas including catalysis, sensing, optoelectronic devices, drug delivery, and biolabeling or even energy storage and devices as well as alternative power sources (such as efficient solar cells). Based on the nature of nanocrystals produced, there are three types of nanotube-nanocrystal hybrid systems, including CNT-metal nanoparticles, CNT-metal oxide nanoparticles and CNT-quantum dots, which will be individually discussed with more details in the following sections.

This field still needs much research since many issues remain unresolved. Firstly, it is difficult to control the rate, density, and spatial localization of functionalization of nanocrystals onto nanotube templates. Secondly, the nature (and adequate detection) of defects in these systems is not well understood. Thirdly, the exact growth mechanisms are not fully understood, and the role of factors in determining the morphology of the final products such as temperature, heating rates, ionic strength, solvent viscosity, as well as the presence of organic ligands are only empirically answered. The large-scale synthesis of such nanomaterial heterostructures has not been developed. Most importantly, health, toxicity, and environmental issues associated with the various synthetic routes of these composite materials need to be promptly dealt with for their general acceptance and applicability in practice.

\section{Inorganic nanomaterials}

\subsection{Metals}

Metallic nanoparticles describe nanosized metals with dimensions (length, width or thickness) with a size range of 1 to $100 \mathrm{~nm}$. Faraday (1857) first found the existence of metallic nanoparticles in solutions and Mie (1908) gave a quantitative explanation of their colour. The number of publications dealing with metallic nanoparticles increases year by year. The most interesting metals being studied are $\mathrm{Au}, \mathrm{Ag}, \mathrm{Pt}, \mathrm{Pd}, \mathrm{Zn}, \mathrm{Cd}$, $\mathrm{Cu}$ and $\mathrm{Fe}$. They exhibit a variety of characteristics offering them special properties; large surface-area-to-volume ratio, large surface energies, transition between molecular and metallic states providing specific electronic structure, plasmon excitation, quantum confinement, short range ordering, increased number of kinks and dangling bonds, offering ability of storing excess electrons.

Bottom-up approaches and especially liquid phase synthesis is used for the production of metallic nanoparticles [59]. The general method of synthesis is the reduction of metal complexes in dilute solutions [96]. In aqueous systems, the reducing agent must be added or generated in situ. However, in nonaqueous systems, solvent and reducing agent can be the same [97]. Monosized metallic nanoparticles are formatted by a combination of a low concentration of solute and polymeric monolayer adhered onto the growth surfaces. The diffusion of growth species from the surrounding solution to the growth surfaces is hindered by a low concentration and a polymeric monolayer. The diffusion process acts as the rate limiting step and as a consequence, uniform nanoparticles are formed [96].

A variety of precursors, reduction reagents and stabilizers are used in the synthesis of metallic colloidal dispersions. The most commonly used precursors are elemental metals, inorganic salts and metal complexes, like $\mathrm{Ni}, \mathrm{Co}, \mathrm{HAuCl}_{4}, \mathrm{H}_{2} \mathrm{PtCl}_{6}$, $\mathrm{RhCl}_{3}$ and $\mathrm{PdCl}_{2}$. As reduction reagents sodium citrate, hydrogen peroxide, hydroxylamine hydrochloride, citric acid, carbon monoxide, phosphorus, hydrogen, formaldehyde, aqueous methanol, sodium carbonate and sodium hydroxide are used. Polyvinyl alcohol and sodium polyacrylate are often used as polymeric stabilizers [96]. Easily oxidized solvents like alcohols can act both as reducing agents and as the colloid diluent. By this way, the alcohol reduction process has been developed by Hirai and Toshima [97].

A variety of physical methods of metallic nanoparticles synthesis has been developed, like sonochemical reduction, supercritical fluids, pulsed laser ablation, plasma, microwave irradiation, gamma radiations and chemical vapour deposition vapour phase synthesis (thermal decomposition of metal salts) or mechanochemical and thermo-mechanical processes can be used for the production of non-precious metals, while silver and gold can be synthesized only by liquid phase precipitation to take advantage of inexpensive raw materials and ease of control of particle sizes [59].

\subsubsection{Gold nanoparticles}

Gold nanoparticles are usually found as colloidal gold, namely a suspension of nanometer-sized particles of gold. The colloidal gold solutions have properties that differ from the bulk gold $[98,99]$. A colloidal solution has either an intense red color, when particles have a size less than $100 \mathrm{~nm}$ or a dirty yellow color, when particles are larger. Gold nanoparticles demonstrate unusual optical properties, due to their interaction with electromagnetic field, which causes oscillation of the free electrons under a particular frequency of the light [100-104]. This process is called localized surface plasmon resonance (LSPR). The surface plasmon can decay radiatively resulting in light scattering or nonradiatively by converting the absorbed light into heat. Gold nanospheres with particle size around $10 \mathrm{~nm}$ in diameter can absorb around $520 \mathrm{~nm}$ in aqueous solution due to their LSPR. These nanoshperes can increase in larger particles, due to the electromagnetic retardation [105].

Properties and applications of colloidal gold nanoparticles depend on their shape, which can be spherical or rod-shaped. 
Rod-shaped nanoparticles have two resonances, on the long and on the short axis, which depends on the nanorod aspect ratio [106]. Rod-shaped particles have both transverse and longitudinal absorption peak. The anisotropy of their shape affects their self-assembly [107]. Gold nanoparticles' applications include biological imaging, electronics, and materials science [108].

Gold nanoconjugates coupled with strongly enhanced LSPR gold nanoparticles have found applications in simpler imaging techniques such as dark-field imaging, surface enhanced Raman scattering (SERS), and optical imaging for the diagnosis of various disease states [109]. It has also been reported that gold nanoparticles can be used as a probe for Raman scatters in vivo, for tumor-targeting. The Raman enhancement from these tailored particles has been observed with electronic transitions at 633 or $785 \mathrm{~nm}$ via SERS [110]. Moreover, gold nanoparticles in photothermal therapy are one of the biggest recent successes, due to the invention of gold nanorods by Murphy and Coworkers, who were able to tune the absorption peak of these nanoparticles, from $550 \mathrm{~nm}$ up to $1 \mu \mathrm{m}$ just by altering their aspect ratio $[111,112]$. Despite the incompatibility presented by gold nanorods with Magnetic Resonance Imaging (MRI) or other high-resolution techniques, it is a big potential to be used as nanoprobes [105].

The most usual synthetic route for the preparation of gold nanoparticles is the reduction of a metal salt in solution, with the help of a stabilizer. A variety of reducing agents and stabilizers have been found and as a result, large amounts of nanoparticles can be produced. According to the method developed by Brust et al., $\mathrm{AuCl}_{4}^{-}$transfers from aqueous to organic solutions, while reduction with $\mathrm{NaBH}_{4}$ occurs, in the presence of alkanethiols. The achieved sizes of gold nanoparticles are between 1 and $3 \mathrm{~nm}[113,114]$.

Solvated metal atom dispersion technique (SMAD) [115, 116] is another method suitable for large quantities synthesis of gold nanoparticles. This method involves the vaporization of gold under vacuum. Inside the walls of the vacuum chamber, which is cooled to liquid nitrogen temperature, deposition of the vaporized gold occurs, in the same time with vapors of organic solvents i.e. toluene. Gold colloids can be easily isolated, because there are no by-products. Nanoparticles' size varies from 1 to $6 \mathrm{~nm}$ and their shape is nearly spherical [114].

Gold nanoparticles are widely produced and offered in the market. They can be found in different forms, such as organic gold, redispersible powders, silica coated or in spheres shaped. $1 \mathrm{mg}$ of organic gold nanoparticles can be found in the price of $€ 20-€ 40$ in Europe. However, gold nanoparticles stabilized in PVP are much more expensive and $1 \mathrm{mg}$ costs about $€ 160$. The price does not change in relation to the nanoparticle size. Generally, gold nanoparticles that are functionalized have an increased price that reaches the price of $€ 200$. In USA, gold nanoparticles $90 \mathrm{~nm}, 99.99 \%$ pure, cost $\$ / \mathrm{g} 350$, which is very close to the price that are disposed in Europe.

\subsubsection{Silver nanoparticles}

Particles of silver, with particle size between 1 and $100 \mathrm{~nm}$ are called silver nanoparticles. Most of the time, silver nanoparticles contain large percentage of silver oxide due to their large ratio of surface to bulk silver atoms. Currently, there is also an effort to incorporate silver nanoparticles into a wide range of medical devices, including bone cement, surgical instruments, surgical masks, etc. Silver nanoparticles can replace silver sulfadiazine for the treatment of wounds. Their physiochemical properties make them suitable for biomedical imaging using SERS. Molecular labeling can be accomplished due to the surface plasmon resonance and the large effective scattering crosssection of individual silver [117]. These novel biomaterials were developed for the reduction of the antibacterial infection. The methodology allows for the first-time silver impregnation (as opposed to coating) of medical polymers and promises to lead to an antimicrobial biomaterial [118].

The typical synthesis includes the reduction of a silver salt with a reducing agent like sodium borohydride in the presence of a colloidal stabilizer. Commonly used stabilizers are polyvinyl alcohol, poly(vinylpyrrolidone), bovine serum albumin (BSA), citrate, and cellulose. $\beta$-d-glucose can be also used as a reducing sugar and a starch as the stabilizer to develop silver nanoparticles ion implantation [119]. The size and shape have been shown to have an impact on its efficacy so all nanoparticles created are equal. Sun and Xia [120] reports the synthesis of monodisperse silver nanocubes by reduction of silver nitrate with ethylene glycol, which works both as a reducing agent and solvent; poly(vinylpyrrolidone) on the other hand is used as a capping agent. Large quantities of high symmetric silver nanocubes can be produced, with varying diameters $(50-100 \mathrm{~nm})$ by controlling the experimental conditions (temperature, metal salt concentration, metal/stabilizer ratio, growth time, etc.) [120]. For the preparation of highly monodisperse myristate-capped silver, a suspension of silver myristate in thiethylamine heated at $80{ }^{\circ} \mathrm{C}$ for $2 \mathrm{~h}$ is prepared. Precipitation of nanoparticles is achieved by acetone and the isolated nanoparticles are obtained in a solid state [121]. Silver nanoparticles, like gold nanoparticles are also widely sold in the market. Their prices are similar to the price of gold nanoparticles.

\subsubsection{Platinum nanoparticles}

Platinum nanoparticles demonstrate catalytic properties for many chemical reactions, such as hydrogen oxidation and oxygen reduction in fuel cell reactions [122]. Chemical reduction techniques have been extensively investigated in the preparation of platinum nanoparticles because these methods can be implemented under simple and mild conditions, and can be used to prepare nanoparticles on a large scale. Platinum nanoparticles can be synthesized by chemical reduction of potassium hexachloroplatinate with trisodium citrate under vigorous stirring and addition of sodium dodecyl sulfate as stabilizer reagent [123]. Except for platinum nanoparticles, 3D platinum nanoflowers can be synthesized by a facile and scalable approach. The ethanol reduction method is used at $85{ }^{\circ} \mathrm{C}$ in the presence of a capping agent PVP-10. The reaction conditions are controlled so the generation and growth of the Pt nanoflowers can lead to these ordered structures [124]. Platinum can be used for the preparation of metal alloys, like FePt; in this case, metal salts are also considered. The production of monodispersed FePt nanoparticles includes an organometallic iron (iron pentacarbonyl), as iron source precursor. A platinum salt (platinum acetylacetonate) is used as platinum precursor. 


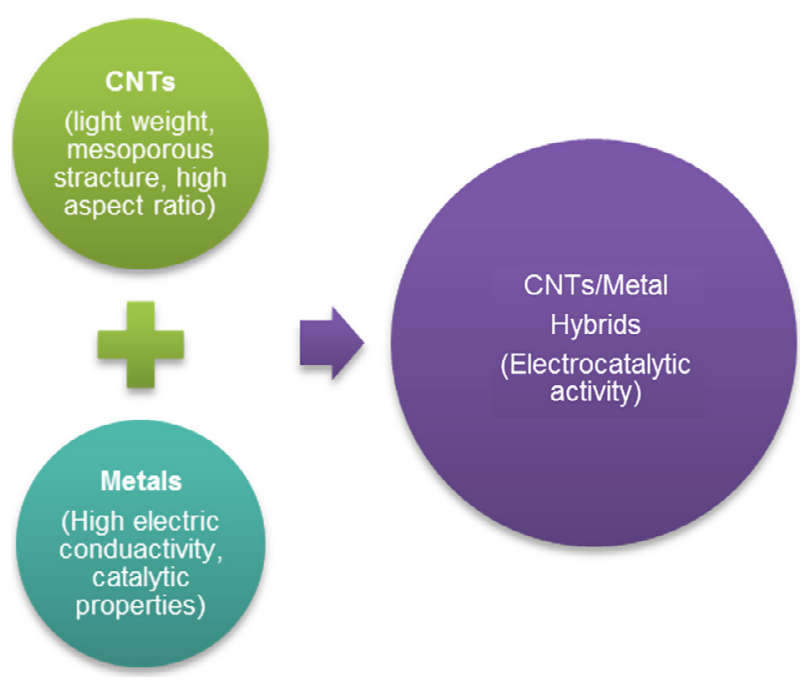

Figure 9. CNTs/Metal Hybrids for enhanced electrocatalytic activity.

Iron pentacarbonyl is added to a $100{ }^{\circ} \mathrm{C}$ solution containing the platinum acetylacetonate and the reducing agent. A simultaneous thermal decomposition of iron pentacarbonyl and the reduction of Pt salt in the present of surfactant, describes the synthesis of FePt nanoparticles $[125,126]$. Platinum nanoparticles are the most expensive; a typical price in Europe is $€ / g 1900$.

\subsubsection{Palladium nanoparticles}

Large-scale production of palladium and nanoparticles can be achieved by thermal decomposition at $300{ }^{\circ} \mathrm{C}$ of a metal acetate solution in a surfactant, which can be either tri-noctylphosphine (TOP) or a mixture of TOP/oleylamine. Highly monodisperse palladium nanocrystals with a size distribution of 3.5 and $7 \mathrm{~nm}$, can be obtained depending on the surfactant mole ratio. Nanoparticles with average size over than $10 \mathrm{~nm}$, can be produced using only oleylamine as surfactant. Advantages of the technique include the quality of the nanoparticles, the ease of preparation and the no need of further selective technique [127]. Palladium is also an expensive metallic nanoparticle; its price can reach $€ / g 1200$.

\subsection{Metal/CNTs hybrids}

Metal nanoparticles can be used in combination with CNTs (Figure 9). The metal nanoparticles are attached on the surface of the CNTs, either as single-walled or multi-walled. For the preparation of the hybrids, several methods have been employed, such as electrochemical deposition with or without reducing agent [128-131], spontaneous reduction [132], physical evaporation $[133,134]$ and solid state reaction with metal salts at elevated temperatures [135, 136].

Since now, a variety of metals have been tested on CNTs; gold and palladium have shown high dispersion along the tube walls. They can be directly produced from a redox reaction between metal ions and reduced CNTs. In this case, surface functionalization of CNTs and use of surfactants in order to access dispersibility, are not necessary. This electrochemical method is easily scaled-up and very promising [137]. On the other hand, Pt nanoparticles can be dispersed in poly(acrylic acid) modified by MWCNTs, through ethylene glycol reduction [138]. The electroless deposition presents many advantages, due to its simplicity and easy scalability. Moreover, thin films of CNTs decorated with copper can be produced and find use in photo-electrochemical devices and several nanoscale structures [139].

These unique materials find application mainly in the field of catalysis. The unique properties of CNTs, such as the nanoscale dimensions, the mesoporous structure with the high aspect ratio and their light weight, render them suitable for catalysts support. At the same time, they present great catalytic activity and both reaction selectivity and pathway [140]. Moreover, Pt/MWCNTs hybrids show high electrocatalytic activity, long-term stability and storage property, which make them ideal for wide use in catalytic applications. Potential applications of these materials include transportation and portable electronic devices, as direct methanol fuel cells [138].

\subsection{Metal oxides}

Metal oxides such as $\mathrm{ZnO}, \mathrm{TiO}_{2}, \mathrm{CeO}_{2}, \mathrm{ZrO}_{2}, \mathrm{CuO}, \mathrm{Al}_{2} \mathrm{O}_{3}$, $\mathrm{NiO}, \mathrm{Fe}_{2} \mathrm{O}_{3}, \mathrm{Fe}_{3} \mathrm{O}_{4}$, etc. have gained much research attention owing to their unique chemical, electrical, magnetic, mechanical, optical properties [141], with a broad range of individual applications in various technological fields. They can be used as semiconductors, pigments in paints, catalysts/photocatalysts, sensors, piezoelectrics, ferrofluids, luminescents, sun screens and UV absorbers, in optical devices, piezoelectric devices, surface acoustic wave devices, high-density information storage, magnetic resonance imaging, solar energy devices, and in medical field as well, such as in magnetic hyperthermia, bioimaging, cell labeling, targeted drug delivery, antibacterial, antioxidant, neutron capture therapy, cancer therapy, etc. As fillers in some suitable polymers would yield several novel potential applications including electronic, food packaging, storing, etc. [142-145].

Based on the vast range of applications of metal oxides, their field has been thoroughly investigated and thousands of reports are found in the literature. Their synthesis techniques have grown exponentially in the past years and depending on their growth mechanism those techniques can be divided into the following categories: catalyst-free and catalyst-assisted procedures which can be further distinguished between vapour and solution phase growth i.e. vapour-liquid-solid (VLS), solutionliquid-solid (SLS) or vapour-solid (VS) process [146]. Initially, the most used procedure for metal oxides synthesis was the vapour phase but along the way it was realized that solution phase growth techniques offer more flexible synthesis processes with even lower production costs [147]. In the last $1 \frac{1}{2}$ decades, the hydrothermal technique which also covers supercritical water or supercritical fluid technology is gaining momentum owing to its enormous advantages in the yield and speed of production of nanoparticles, ease of operation, low temperature, 
low cost, environmentally benign process and also it offers high product purity and homogeneity, crystal symmetry, narrow particle size distributions, etc. and it is becoming one of the most important tools for advanced materials processing [142, 148, 149]. The synthesized metal oxides nanostructures have various morphologies depending on the production method and its parameters including nanoparticles, nanofibres, nanowires, nanoneedles, nanorods, nanorings, nanoplates, nanotubes, nanocages, nanospheres, nanohelices (or spirals) hollow spheres, etc. [146, 150-154].

According to research undertaken by Abercade Company in 2009 [155], metal oxides constituted the $80 \%$ of the nanopowder market volume, while the share for fine metal powder was only $15 \%$. The other $5 \%$ was shared between complex metal oxides and fine metal powder mixtures. Those percentages were expected to be increased by 2015 .

\subsection{Metal oxides/CNTs hybrids (nanocomposites)}

Metal oxides or hydroxides such as $\mathrm{MnO}_{2}$ [156], $\mathrm{Fe}_{3} \mathrm{O}_{4}$, $\mathrm{RuO}_{2}, \mathrm{Ni}(\mathrm{OH})_{2} \mathrm{Co}_{3} \mathrm{O}_{4}, \mathrm{TiO}_{2}[149,157], \mathrm{MgO}$ [158], etc. have been successfully deposited on CNTs to fabricate nanocomposites, also solving the problem of CNT agglomeration in solutions without the use of surfactants [159]. These oxides can be deposited as a continuous amorphous or single-crystalline film with controlled thickness, or as discrete units in the form of nanoparticles, nanorods, or nanobeads. The resulting nanocomposites integrate the unique characters and functions of the two types of components and may also exhibit some new properties caused by the cooperative effects between the two kinds of materials [160].

The deposition can be carried out either in solution via electrochemical reduction of metal salts, electro- or electroless deposition, sol-gel processing [161], and hydrothermal treatment with supercritical solvents, or from the gas phase using chemical deposition (CVD or ALD) or physical deposition (laser ablation, electron beam deposition, thermal evaporation, or sputtering). Such composites have promising new applications in many fields such as mechanics, optics, electronics, catalysis, gas sensors and chemical sensors, supercapacitors and batteries, field emission devices and in biology [149].

\subsection{Quantum dots (QD)}

Colloidal semiconductor nanocrystals, which are also known as quantum dots (QDs), are monodisperse crystalline clusters with physical dimensions smaller than the bulk-exciton Bohr radius [162]. A typical QD has a diameter of about 2-10 nm. A variety of QDs have been prepared, usually composed of atoms from groups II-VI, III-V, or IV-VI, which include CdSe, CdTe, ZnSe, CdS, CdSe/ZnS, In, etc. [163]. The following methods have been conducted for the synthesis of semiconductor quantum dots [164]:

- Precipitation method, usually aqueous and at low temperature.

- Reactive methods in high boiling point solvents, often involving metal organic and/or organometallic compounds.
- Hydrothermal and solvothermal methods.

- Vapour phase reactions.

- Reactions in confined solids or constrained on surfaces or involving micelles or confined reaction spaces.

- Microwave irradiation method [165, 166].

- Ultrasound irradiation [167].

Theoretical research has been done for the experimental synthesis and characterization of graphene quantum dots (GQDs). Current synthesis methods including top-down and bottom-up approaches (e.g. nanolithography or from chemical breakdown of the extended planar structure of graphene oxide (GO)), are either expensive, very harsh, they do not result in well-defined particles or they are extremely inefficient [168]. A proposed top-down method has demonstrated a large scale and facile synthesis of GQDs by acidic exfoliation and etching of pitch carbon fibres, that are cheap and available materials composed of distributed graphitic domains. Their size distribution could be tailored by choosing different reaction temperatures [167]. In general, an efficacious method that allows for the large-scale synthesis of GQDs of well-defined size and chemical functionality is still lacking. However, their unique properties render them an exciting future material with potential applications in diverse areas spanning from energy harvesting and storage to bioanalytics [168] and supercapacitors [170] would certainly boost research and applications in this area.

The market of quantum dots still remains small and only few companies sell dots for research purposes. What is more, their extremely high price that fluctuates between US\$3000 to $\$ 10,000$ per gram restricts their use to highly specialized applications. But this would change over the next years, as it is predicted by industry analysts, since more efficient manufacturing processes are currently sought by scientists $[164,171]$. The latter is driven by their unique size-depended electro-optical properties such as sharp and symmetrical emission spectra with high quantum yield, good photostability and chemical stability, sizedependent emission-wavelength tunability, and exhibition of the localized surface-plasmon resonance (LSPR) phenomenon, catalytic properties for redox reactions, size dependent catalytic action and controllable charge and electron transfer event [163, 172]. QDs potential applications in nanomedicine are numerous spanning the areas of imaging, therapy, drug delivery, and nanodiagnostic; however their toxicity issues still remain an obstacle for their use in vivo, while their applications in vitro are likely to expand quickly in the coming few years [173].

QDs toxicity depends on multiple factors derived from both inherent physicochemical properties and environmental conditions; QD's size, charge, concentration, outer coating bioactivity (capping material and functional groups), and oxidative, photolytic, and mechanical stability [174]. For QDs up-scaling, much research should be performed, elucidating the mechanisms of every individual QD actions as well as its environmental transport and fate covering, also nanotoxicological studies.

\subsection{Quantum dots/CNTs hybrids}

CNTs possessing a large chemically active surface area are powerful candidates for supporting semiconductor 
nanoparticles, e.g. QDs. The QDs may be linked directly or indirectly to the CNT surface by covalent or noncovalent bonds. The conjugation of nanomaterials to the CNT via covalent bonding may be achieved using acid solutions that functionalize the surface of these materials to provide a suitable platform for the CNTs to form covalent bonds with QDs. For the indirect bonding, an intermediate molecule such as a polymer that has previously been conjugated to either the CNT or the QD is needed $[95,175,176]$.

QDs/CNTs hybrids are regarded as one of ideal candidate materials for the fabrication of nanoscale optoelectronic devices, such as photodetector, photoswitch and solar cells $[169,177]$ for medical diagnosis and treatment $[175,178]$ or even as catalysts for the oxygen electrodes of low-temperature fuel cells [179].

\section{Life cycle assessment (LCA) and nanomanufacturing}

With the rapid emergence of materials and products designed using nanotechnology, concerns have escalated regarding the potential for adverse biological and environmental effects. Parameters like energy consumption both for the nanomaterials' production and the construction of facilities and equipment [180], water utilisation and long-term impacts, such as greenhouse gas emissions [181], which are associated to nanoproducts should be reassessed during their life cycle. Traditional waste management methods should be replaced due to the advances in nano-ecotoxicology that can detect trace levels of nanowastes [182].

Through a life cycle assessment (LCA) a variety of impacts can be assessed. First of all, environmental problems like global warming, acidification, eutrophication, ozone depletion and ecotoxicity can be determined. Effects on human health can also be assessed; carcinogenesis, respiratory effects, human toxicity, life expectancy are the main fields that are under study. Finally, the use of non-renewable energy, resources as well as the end-of-use of products causing hazardous wastes are investigated [183].

LCA is a tool that has been designed for the quantification of the environmental impacts of a system. It can provide a framework for the identification and measurement of all sources of nanowaste, while it examines upstream processes (manufacturing of precursors, components, equipment, etc.) as well as downstream processes (nanowastes' capture, recycling, treatment and disposal). The levels of nanowastes tend to vary in each chain activity; as a result it is important to collect data carefully from all stages of life cycle (importing, retailing, product usage, waste treatment, etc.) [182]. LCA can be considered as an ecodesign tool, while it can predict the environmental improvements that should be done in a new-designed nanoproduct, from the early stages in the laboratory [184]. Therefore, it is possible to evaluate the toxicological properties of nanomaterials before their production stage [185].

However, LCA has to face many challenges, especially when it is applied for decision making in scaling issues, including process selection, design and optimization [186]. Its uncertainty is associated to the unknown future applications of the produced nanomaterials and the unknown industrial scales that will be implemented for their mass production. In this point, the difficulty in comparing laboratory and industrial data for the production of the nanomaterials should be mentioned, while both laboratory methods and equipment are differentiated [184]. Moreover, the existing life cycle inventory (LCI) databases do not contain datasets for nanomaterials and the only way to proceed to the assessment is to device a custom database with all data that can be collected. There is also a lack of emission factors of the nanomaterials into different environments (air, water, soil) [187]. Computational methods using several models have been developed to bridge this gap, but the calculated emissions conceal uncertainty. It is obvious that the lack of information about the life cycle of nanoproducts results in the ignorance towards potential environmental problems that can be caused during nanomanufacturing.

For the nanoproducts that are already in the market, few LCA studies have been conducted and they are related to laboratory and pilot synthesis [184]. In most studies, only the energy usage and chemical consumption are noted [188-190]. A recent review [191] gathers the environmental impacts that have been reported from several LCA studies for CNTs. Meagan et al. investigated three production methods of SWCNTs; arc ablation, chemical vapour deposition and high pressure carbon monoxide [192]. An evaluation for environmental impacts of CNFs has also been executed by Khanna and Campion [193]. Moreover, FP7 Project named NanoSustain (Development of sustainable solutions for nanotechnologybased products based on hazard characterization and LCA) deals with case studies of nanotechnology-based applications, such as MWCNTs in epoxy plates, nano- $\mathrm{TiO}_{2}$ in paint applications and nano-ZnO glass coating as UV-barrier for glass [194].

In order to expand the use of LCA to work as a tool for industrially produced NMs, it is necessary to gather data from all existing industries which already produce them. In terms of research, the toxicity of new developed nanomaterials should be checked. Experimental data on characteristics and toxicity of nanoparticles can also be collected from recent research projects that are involved in nanomanufacturing [195]. Complete databases need to be developed, which will include each nanomaterial. All data of the characteristics of nanomaterials, depending on the method of their preparation, can be collected in a European platform. As a result, anyone interested can refer to it and collect data to perform LCA study, which can be combined with adapted exposure and fate modeling, in order to have complete results of nanoproducts during all life cycle stages. Finally, LCA results can be combined with risk assessment to obtain a comprehension between interactions of nanomaterials and environment and to predict the potential damage on environment and human health due to nanomaterials manufacturing and use.

\section{Current applications}

The unique properties of nanomaterials have a broad range of applications in many industries. In 2010, 1317 consumer goods were already estimated in the market, which incorporate nanomaterials, taking advantage of the nanomaterials unique properties, while this number is steadily increasing every year. Among them, only 313 products use inorganic nanomaterials, 
while the $50 \%$ of which (313 products) contain silver nanoparticles for antibacterial purposes. Carbon in the form of CNTs and titanium oxide are the second and third most used in these 313 products. The other remaining 1004 products out of 1317 contain either non-specific chemicals or nanofilms or nanoscale wax particles. Approximately 450 of the 1317 products are personal care products including cosmetics and sunscreens and textile-related products $(\sim 200)$ [196-200].

Some of these available products include the following [196, 201]:

- Non-scratch glasses, on which tissues made of ultra-fine polymers exist with protective and anti-glare properties.

- Building materials (cement, tiles, grouts, sealants, windscreen glass) that are coated with nanoparticles of titanium oxide obtaining advanced functions such as self-cleaning, anibacterial, anti-mould, anti-fungal, antifouling, anti-fogging and deodorizing.

- Clothes with advanced properties such as UV blocking, infrared reflecting, antibacterial, crease-proof, stain-resistance, water-repellence, moisture-control, flame-retardant, odour removing, antistatic, electric conductivity, heat retaining, temperature regulating, wrinkle resistance and high mechanical strength. Such examples are ties that repel dirt, shirts that do not need ironing or skiing anoraks that use nanofibres to resist water and wind.

- Automotive and aerospace technology. Nanoparticle additives in engine-construction materials for lighter weight, higher strength, improved temperature/corrosion resistance and superior wear resistance. Metal oxide nanoparticles, CNTs and CNFs as additives in polymer nanocomposites for densification, and improved mechanical strength and wear resistance of structural materials, tyres, etc. Additionally, in sports equipment, such as tennis rackets with CNTs to make them more flexible and more resistant.

- More effective and protective cosmetics. Lotions granulated to below $50 \mathrm{~nm}$ that let light through, giving a purer, cleaner feel. Anti-wrinkle creams that use polymer nanocapsules to distribute active agents such as vitamins more efficiently. Sun creams that use nanoparticles of titanium dioxide and zinc oxide, so they do not turn white when spread on the skin, while they offer the same degree of protection against UV light as traditional creams.

- Antibacterial agents. Silver nanoparticles are used as an antibacterial agent in many consumables ranging from surgical instruments and household appliances to pet food bowls.

Some applications of nanomaterials that are close to industrial level include [202]:

- Hydrogen storage (specifically metals or ceramics nanostructured materials).

- Delivery of pharmaceuticals in nanocapsules (hollow nanoparticles).

- Catalysts, adsorbents and absorbents as nanoporous materials (e.g. in vehicles in filters for reducing environmental pollution and fuel consumption).
- Nanoscale electronic and optical instruments (nanocables).

- Environmental protection (dendrimers exhibiting high degree of surface functionality and versatility can act as "attractors" of metal ions.

There also some applications of certain nanomaterials under investigation:

\subsection{Carbon nanotubes}

CNTs exhibit extraordinary molecular properties rendering them applicable to many fields such as fillers in polymer matrices for better mechanical performance (e.g. for the manufacturing of more powerful windmills, in automotive or in construction) [196, 201-203] and improvement of electrical conductivity [204, 205], energy storage (in supercapacitors or lithium ion batteries) and energy conservation technology [196, 206-208], biotechnology [209], medicine (in bone replacement), field emission devices (e.g. transistors and displays), nanosensors, storage of hydrogen and ions, solar cells [196].

\subsection{Carbon nanofibres}

A wide spectrum of CNFs includes their use in gas storage, energy storage and energy conservation technology, catalysts' support, polymer additives and tissue scaffolds [196, 210-214].

\subsection{Fullerenes}

Fullerenes have shown drug targeting capability and exhibit antioxidant and antimicrobial behavior. They also act as superconductors at very low temperatures. Their current applications include lubricants and solar cells [196, 201, 215, 216].

\subsection{Metal and metal oxides nanoparticles}

Metal and metal oxides nanoparticles exhibit size and shape-dependent properties that gain al lot of interest for applications ranging from catalysis and sensing to solar cells, optics, data storage and as antibacterial agents. Ceramic nanoparticles such as cerium oxide and silicon oxide are enhancing the efficiency of fuel cells in a variety of ways. Many semiconductor nanoparticles can act as photocatalysts to split water in hydrogen generation. Electrochromic windows made with tungsten oxide nanoparticles exhibit enhanced thermal insulation. Zinc oxide and titanium oxide as UV-shielders can increase the durability and product lifetime of many organic materials (plastic, wood, textiles, paints) [196]. The applications of gold nanoparticles mainly include imaging [217], cancer diagnosis and drug delivery [218] due to their intriguing optical and physical properties. Silver nanoparticles have been extensively used as antibacterial agents, surface disinfection applications [219-221] and catalysts [222]. A wide range of nanosilver applications has emerged in consumer products ranging from disinfecting medical devices and home appliances to water treatments and 
air purification. Platinum and palladium nanoparticles are among the most efficient metals used in many catalytic processes, including fuel cells [196, 223-225].

\subsection{Quantum dots}

The quantum dot is defined as a particle of matter so small that the addition of a single electron will alter its properties. Quantum dots can be manufactured from semi-conducting material, comprising only a few hundred atoms, and when excited they emit light at different wavelengths depending on their size, which makes them extremely useful as biological markers of cell activity. Therefore their possible applications are the following: light emitters, LED lasers in optoelectronics, quantum cryptography for invisibly marking documents or banknotes, biomarkers and biosensors, quantum computing, solar cells [196, 201].

\subsection{Current status}

Many companies are engaged to perform analyses of the current and future market size for nanotechnology. Most of their reports predict that nanotechnology markets will be tens of billions of dollars in the near future. The continuous progress in product development and market acceptance will spread the use of nanoparticle technology further, wider and deeper in many industries [196].

\section{Conclusions and perspectives}

The existence of nanomaterials has been known for centuries; examples of which are the carbon black, fumed silica, titania; their industrial applications dated since the 1900s [201, 226, 227]. Over the years research has provided researchers with a better understanding of the mechanisms involved during the synthesis of nanomaterials, their intrinsic properties affecting from increased surface area and quantum effects, and it still leads to the development of advanced analytical techniques for their characterization and their systematic tailored synthesis. Since many industrial sectors (such as aerospace, energy, transportation, and medicine) are highly benefited and improved by the application of nanomaterials, their demand is increasingly growing. The available consumer products containing nanomaterials (as particles or fibres) most commonly carbon, cerium oxide, silver, silica, titanium dioxide, magnesium oxide and zinc oxide now exceeds the number of 1000 and is still raising $[196,227]$. However, apart from the advantages that nanotechnology offers to society, it may also have negative impacts on human health and the environment which are not yet understood, since the quantum mechanics which regulate nanomaterials' interactions with other substances also make their toxicological behavior difficult to predict [227].

Although the existing regulations appear adequate to manage the risks of nanotechnology at its current stage of development, further research is needed concerning the toxicological and ecotoxicological properties of nanoparticles, their uptake in the body, accumulation in the tissues and organs, transport characteristics, exposure and dose/response data, their distribution and persistence in the environment [228]. As a result, the lack of a suitable regulatory framework and guidance on safety requirements renders manufacturers reluctant to develop new products containing nanomaterials [227]. The latter can be overcome by a systematic scientific approach to the study of nanoparticle toxicity that requires its correlation with the physical and chemical characteristics properties of nanoparticles (such as exact composition, crystallinity, size, size dispersion, aggregation, ageing). Moreover, research should also be directed to the ecological and environmental implications of natural and anthropogenic nanoparticles pollution [229]. To this direction, a number of organizations, including federal bureaus such as the EPA and testing standards developers such as ASTM, have begun developing methods to assess nanomaterial properties, such as LCA methodology [227]. Hopefully, the engineered nanomaterials will be manipulated with more cautious in the future and new laws and policies will manage all aspects of nanomaterial manufacturing, industrial use and recycling.

Summarizing, there are five critical success factors for nanotechnology growth and development thoroughly explained in literature [230]:

\section{- Product orientation (and not technology admiration)}

- This factor should satisfy both of the following needs: focusing on the single most viable and attainable application and starting to make an exhaustive list of potential applications.

- Continuous industry interaction and selection of a beachhead application

- Focusing on the development of the single most viable and attainable product opportunity once known, to the exclusion of all else, until it is successfully scaled-up or it fails.

- Application of spiral product development methodology

- Engaging with lead users and utilizing iterative product development to increase the probability that the product meets the customer's wants and needs.

- Attraction and retention of industry partners

Attracting and retaining investors and corporate partners through effective sharing of context-rich technology knowledge to reduce the risk from an absence of universal product development milestones that represents an increase in value for the nanotechnology venture to justify.

- Mitigation of nanotechnology - specific technology risks Identifying and addressing technical risks which may exist in relation to cost, quality control and tolerance of the nanotechnology in the manufacture, including occupational and environmental health and safety considerations.

Acknowledgements. The support from the EU FP7 Project "Functionalized Innovative Carbon Fibres Developed from Novel Precursors with Cost Efficiency and Tailored Properties" (FIBRALSPEC) under Grant Agreement no. 604248 is greatly acknowledged by CAC, PCG, MAK, AFT and VK. 


\section{References}

1. R. Naseri, R. Davoodi, in Proceedings of the 3rd International Conference on Information and Financial Engineering, Shanghai, 2011, JOEBM (Ed.).

2. A. Busnaina et al., J. Nanopart. Res. 15 (2013) 1984.

3. W. Luther et al., in Growth market nanotechnology: an analysis of technology and innovation, N. Malanowski, T. Heimer, W. Luther, M. Werner (Eds.), Wiley-VCH Verlag GmbH \& Co, KGaA, Weinheim, 2007.

4. European Commission, Community Research and Development Information, [http://cordis.europa.eu/].

5. A. Gurav et al., Aerosol Sci. Technol. 19 (1993) 04.

6. H.K. Kammler et al., AIChE J. 47 (2001) 07.

7. T.T. Kodas, M.J. Hampden-Smith, Aerosol processing of materials. 6th ed., Wiley-VCH, New York, 1999.

8. W. Luther, in Industrial application of nanomaterials-chances and risks, W. Luther (Ed.), Future Technologies Division, Dusseldorf, 2004.

9. A. Gohier et al., Appl. Surf. Sci. 258 (2012) 6024.

10. A.H. Pfund, Phys. Rev. 35 (1930) 1434.

11. G. Skandan, A. Singhal, in Nanomaterials handbook, Y. Gogotsi (Ed.), Taylor \& Francis Group, Florida, 2006.

12. M.T. Swihart, Curr. Opin. Colloid Interface Sci. 8 (2003) 127.

13. BUONAPART-E [www.buonapart-e.eu].

14. T. Pfeiffer, J. Feng, A. Schmidt-Ott, Adv. Powder Tech. 25 (2014) 01.

15. J. Wei, F.E. Kruis, Chem. Eng. Sci. 104 (2013) 451.

16. V. Dudoitis et al., Lith. J. Phys. 51 (2011) 03.

17. P. Sudarsanam, B.M. Reddy, in Nanotechnology commercialization, T. Tsuzuki (Ed.), Pan Stanford Publishing, Singapore, 2013.

18. S. Buzby, S. Franklin, S. Shah, Synthesis, properties, and applications of oxide nanomaterials, Wiley, Canada, 2007.

19. D. Vollath, K.E. Sickafus, NanoStruct. Mater. 1 (1992) 427.

20. D. Vollath, Mater. Res. Soc. Symp. Proc. 347 (1994) 629.

21. D. Vollath, Nanomaterials: an introduction to synthesis, properties and applications, Wiley-VCH, Weinheim, 2008.

22. M.L. Hitchman, K.F. Jensen, Chemical vapour deposition: principles and applications, Academic Press, New York, 1993.

23. M. Kumar, Y. Ando, J. Nanosci. Nanotechnol. 10 (2010) 3739.

24. Y. Xu, Y. Xiu-Tian, Chemical vapour deposition: an integrated engineering design for advanced materials series, Springer, London, 2010.

25. S.M. Watson, K.S. Coleman, A.K. Chakraborty, ACS Nano 2 (2008) 04.

26. S.E. Iyuke et al., Nanotechnology 20 (2009) 375602.

27. K.V. Prashant, D. Meisel, Stud. Surf. Sci. Catal. 103 (1997) 237.

28. J.H. Fendler, Korean J. Chem. Eng. 18 (2001) 1.

29. K. Byrappa, M. Yoshimura, Handbook of hydrothermal technology, William Andrew Publishing, New York, 2001.

30. M. Rajamathi, R. Seshadr, Curr. Opin. Solid State Mater. Sci. 6 (2002).

31. A. Addamiano, J. Electrochem. Soc. 108 (1961) 11.

32. X.Z. Zhao et al., Nature 385 (1997) 5.

33. C.N.R. Rao, A. Mueller, A.K. Cheetham, The chemistry of nanomaterials: synthesis, properties and applications, WileyVCH, Weinheim, 2004.
34. Shyman Project [www.shyman.eu].

35. F. Mato et al., in Proceedings of the III Iberoamerican Conference on Supercritical Fluids, Colombia, 2013.

36. T.J. Mason, Sonochemistry, Royal Society of Chemistry, Cambridge, 1990.

37. M. Esmaeili-Zare, M. Salavati-Niasari, in Proceedings of the International Conference Nanomaterials: Applications and Properties, Ukraine, 2013 (NAP, 2013), pp. 1-3.

38. S.M. Zhou, Y.S. Feng, L.D. Zhang, Mater. Lett. 57 (2003) 19.

39. H. Fect, in Nanomaterials: synthesis, properties and applications, A.S. Edelstein, R.C. Cammaratra (Eds.), Taylor \& Francis, Washington, 1996.

40. L.W. Johnson, Prog. Mater. Sci. 30 (1986) 02.

41. M.S. El-Eskandarany et al., Mater. Sci. Forum 88-90 (1992).

42. A. Calka, Appl. Phys. Lett. 59 (1991) 13.

43. A. Calka, J.S. Williams, Mater. Sci. 88-90 (1992) 801.

44. W.E. Kuhn et al., Powder metallurgy, 2nd ed., American Society of Metals, USA, 1998.

45. F. Cerrina, C. Marrian, MRS Bull. 21 (1996).

46. U. Heiz, W.D. Schneider, Crit. Rev. Solid State Mater. Sci. 26 (2001).

47. J.M. Gibson, Phys. Today 50 (1997) 56.

48. S. Matsui, Y. Ochiai, Nanothechnology 7 (1996) 03.

49. S.H. Hong, J. Zhu, C.A. Mirkin, Science 286 (1999) 5439.

50. J.A. Dagata, Science 270 (1995) 5242.

51. M.D. Levenson et al., Solid State Technol. 38 (1995) 9.

52. P.N. Dunn, Solid State Technol. 37 (1994) 49.

53. C. Mirkin, M. Tuominen, Nanotechnology research directions for societal needs in 2020, Springer, The Netherlands, 2011.

54. J. Zha, H. Roggendorf, in Sol-gel science, C.J. Brinker, G.W. Sherer (Eds.), Academic Press, New York, 1990.

55. N. Carbrera, N.F. Mott, Rep. Prog. Phys. 12 (1949) 163.

56. R.D. Piner, C.A. Mirkin, Langmuir 13 (1997) 6864.

57. Y. Li, B.N. Maynor, J. Liu, J. Am. Chem. Soc. 123 (2001) 2105.

58. L.M. Demers et al., Angew. Chem. Int. Ed. Engl. 40 (2001) 3071.

59. Nanoparticle.com, Particle suppliers and standards [http://nanoparticles.org/standards/\#Suppliers]; [http://nanoparticles.org/ standards/].

60. H.W. Kroto et al., Nature 318 (1985) 162.

61. G. Andrievsky, V. Klochkov, L. Derevyanchenko, Fuller. Nanotub. Carbon Nanostructures 13 (2005) 04.

62. K. Kikuchi et al., Chem. Phys. Lett. 188 (1992) 03-04.

63. A. Mateo-Alonso, N. Tagmatarchis, M. Prato, Nanomaterials handbook, Taylor \& Francis Group, Florida, 2006.

64. L. Lamb, D. Huffman, J. Phys. Chem. Solids 54 (1993) 12.

65. W. Krätschmer et al., Nature 347 (1990) 345.

66. J. Howard et al., Nature 352 (1991).

67. C. Lieber, C. Chen, Solid State Phys. 48 (1994) 109.

68. A.A. Bogdanov, D. Deininger, G. Dyuzhev, Tech. Phys. 45 (2000) 521.

69. H. Murayama et al., Fuller. Nanotub. Carbon Nanostructures 12 (2004) 01-02.

70. H. Takehara et al., Carbon 43 (2005) 311.

71. E. Ulloa, EEE-5425 1 (2013) [http://web.eng.fiu.edu/ vlassov/ EEE-5425/Ulloa-Fullerenes.pdf].

72. V. Cebolla, L.V.J. Membrado, in Encyclopedia of separation science, I.D. Wilson (Ed.), Academic Press, Oxford, 2000. 
73. V. Postnov et al., Nanosyst. Phys. Chem. Math. 4 (2013) 05.

74. H. Keypour, M. Noroozi, A. Rashid, J. Nanostructure Chem. 3 (2013) 45.

75. Nanomaterial Suppliers - Fullerenes [www.nanowerk.com/ nanotechnology/nanomaterial/suppliers_plist.php?subcat1=ful].

76. C. Singh, R. Sukhdev, Opt. Eng. 43 (2004) 02.

77. T. Otsubo, Y. Aso, K. Takimiya, Pure Appl. Chem. 77 (2005) 12.

78. F. Diederich, Pure Appl. Chem. 77 (2005) 11.

79. B.K.B. Teo et al., in Encyclopedia of nanoscience and nanotechnology, H. Singh Nalwavol (Ed.), USA, 2003.

80. A.R. Murray et al., Part. Fibre Toxicol. 9 (2012) 10.

81. N. Tagmatarchis, M. Prato, J. Mater. Chem. 14 (2004) 437.

82. K.P. De Jong, J.W. Geus, Cat. Rev. 42 (2000) 04.

83. S. Iijima, Nature 354 (1991) 56.

84. E. Pop et al., Nano Lett. 6 (2006) 01.

85. M.F. De Volder et al., Science 339 (2013) 535.

86. R. Ravindra, R.B. Badekai, Nanomat. Nanotechnol. 2 (2012) 05 .

87. Q. Zhang et al., Chem. Sus. Chem. 4 (2011) 1745.

88. C. See, A. Harris, Ind. Eng. Chem. Res. 46 (2007) 04.

89. J. Huang et al., Chin. Sci. Bull. 57 (2012) 02-03.

90. BCC Research, Global Markets and Technologies for Carbon Nanotubes Report No. NAN024E, 2012

91. S. Bachilo et al., J. Am. Chem. Soc. 125 (2003) 37.

92. Y. Wang et al., Nano Lett. 5 (2005) 06.

93. H. Liu et al., Carbon 48 (2010) 01.

94. S. Huang et al., J. Am. Chem. Soc. 131 (2009) 06.

95. X. Peng et al., Chem. Soc. Rev. 38 (2009) 1076.

96. G. Cao, Nanostructures \& nanomaterials: synthesis, properties \& applications, Imperial College Press, Washington, 2004.

97. R. Wang, in Nanoparticles: from theory to application, G. Schmid (Ed.), Wiley-VCH, Weinheim, 2004.

98. M.A. Hayat, in Colloidal gold: pronciples, methods and applications, M.A. Hayat (Ed.), Academic Press, San Diego, 1989.

99. P.E. Peter, J.T. Meurig, Angew. Chem. 119 (2007) 5576.

100. P.K. Jain et al., Acc. Chem. Res. 41 (2008) 12.

101. P.K. Jain et al., J. Phys. Chem. B 110 (2006) 7238.

102. K.L. Kelly et al., J. Phys. Chem. B 107 (2002) 668.

103. U. Kreibig, M. Vollmer, Mater. Sci. 25 (1995) 532.

104. S. Link, M.A. El-Sayed, Annu. Rev. Phys. Chem. 54 (2003) 331.

105. V.V. Mody et al., J. Pharm. Bioall. Sci. 2 (2010) 04.

106. C.J. Murphy et al., J. Phys. Chem. B 109 (2005) 29.

107. V. Sharma, K. Park, M. Srinivasarao, Mater. Sci. Eng. R 65 (2009) $1-3$.

108. R.C. Rao et al., Chem. Soc. Rev. 29 (2000) 27.

109. I.H. El-Sayed, X. Huang, M.A. El-Sayed, Nano Lett. 5 (2005) 05.

110. X. Qian et al., Nat. Biotechnol. 26 (2008) 83.

111. L. Tong et al., Photochem. Photobiol. 85 (2009) 01.

112. B.D. Busbee, S.O. Obare, C.J. Murphy, Adv. Mater. 15 (2003) 05.

113. M. Brust et al., Chem. Commun. 7 (1994).

114. O. Masala, R. Seshadri, Annu. Rev. Mater. Res. 34 (2004).

115. S. Lin, M.T. Franklin, K.J. Klabunde, Langmuir 2 (1986) 02.

116. S. Stoeva et al., J. Am. Chem. Soc. 124 (2002) 10.

117. S. Schultz et al., Proc. Natl. Acad. Sci. 97 (2000) 03.

118. F. Furno et al., J. Antimicrob. Chemother. 54 (2004) 06.
119. A.L. Stepanov, V.N. Popok, D.E. Hole, Glass Phys. Chem. 28 (2002) 02.

120. Y. Sun, Y. Xia, Science 298 (2002) 5601.

121. M. Yamamoto, M. Nakamoto, J. Mater. Chem. 13 (2003).

122. B.C.H. Steele, A. Heinzel, Nature 414 (2001).

123. H. Mohammadi et al., Int. Nano Lett. 3 (2013) 28.

124. A. Dandapat et al., Nanomater. Nanotechnol. 3 (2013) 11.

125. S. Sun et al., Science 287 (2000) 5460.

126. C. Hongtao et al., Recent Pat. Nanotechnol. 3 (2009) 01.

127. S.W. Kim et al., Nano Lett. 3 (2003) 09.

128. B. Quinn, C. Dekker, S.G. Lemay, J. Am. Chem. Soc. 127 (2005) 17.

129. J. Li, M. Moskovits, T.L. Haslett, Chem. Mater. 10 (1998) 07.

130. L. Qu, L. Dai, J. Am. Chem. Soc. 127 (2005) 31.

131. L. Qu, L. Dai, E. Osawa, J. Am. Chem. Soc. 128 (2006) 16.

132. H.C. Choi et al., J. Am. Chem. Soc. 124 (2002) 31.

133. J. Kong, M. Chapline, H. Dai, Adv. Mater. 13 (2001) 18.

134. Y. Zhang, H. Dai, Appl. Phys. Lett. 77 (2000) 19.

135. R.M. Lago et al., J. Chem. Soc. Chem. Commun. 13 (1995).

136. B. Xue et al., J. Mater. Chem. 11 (2001) 09.

137. E. Lorençon et al., ACS Appl. Mater. Interfaces 1 (2009) 10.

138. F. Zhang, G. Guo, J. Fang, Mater. Res. Bull. 46 (2011) 06.

139. M. Scarselli et al., J. Nanosci. Nanotechnol. 11 (2011) 10.

140. H.P. Rohaya, M. Abdul Rahman, Recent. Pat. Eng. 6 (2012) 01.

141. M. Yang, J. He, J. Colloid Interface Sci. 368 (2012) 01.

142. K. Byrappa, T. Adschiri, Prog. Cryst. Growth Charact. Mater. 53 (2007).

143. K. Byrappa, S. Ohara, T. Adschiri, Adv. Drug Deliv. Rev. 60 (2008).

144. C.C. Berry, in Nanobiotechnology: inorganic nanoparticles vs. organic nanoparticles, J.M. de la Fuente (Ed.), Elsevier, Great Britain, 2012.

145. P. del Pino, P. Beatriz, in Nanobiotechnology: inorganic nanoparticles vs. organic nanoparticles, frontiers of nanoscience, J.M. de la Fuent, V. Grazu (Eds.), Elsevier, Great Britain, 2012.

146. J. Lu, P. Chang, Z. Fan, Mat. Sci. Eng. R 52 (2006) 01-03.

147. E. Comini et al., Prog. Mater. Sci. 54 (2009).

148. K. Namratha, K. Byrappa, J. Supercrit. Fluids 79 (2013).

149. K. Namratha, K. Byrappa, Prog. Cryst. Growth Charact. Mater. 58 (2012) 01.

150. S. Pavasupree et al., Sci. Technol. Adv. Mater. 6 (2005) 03-04.

151. J. Li et al., J. Colloid Interface Sci. 426 (2014) 90.

152. H. Ogihara et al., J. Solid State Chem. 182 (2009) 06.

153. L. Pei, Mater. Charact. 59 (2008) 05.

154. H. Cui et al., Recent Pat. Nanotechnol. 3 (2009).

155. Industrial News, Metal oxides constitute $80 \%$ of the nanopowder market volume [www.abercade.ru/en/materials/ industrynews/443.html].

156. G. Wang et al., Solid State Ion. 176 (2005) 11.

157. A. Kongkanand, R. Dominguez, P. Kamat, Nano Lett. 7 (2007) 03.

158. B. Liu et al., Energy Fuels 21 (2007) 03.

159. R. Kalubarme et al., Nanotechnology 24 (2013) 36.

160. Y. Hu, C. Guo, in Carbon nanotubes and carbon nanotubes/ metal oxide heterostructures: synthesis, characterization and electrochemical property, Dr.M. Naraghi (Ed.), InTech, 2011.

161. T. Sainsbury, D. Fitzmaurice, Chem. Mater. 16 (2004) 11. 
162. S. Kudera et al., in Semiconductor nanocrystal quantum dots: synthesis, assembly, spectroscopy and applications, A. Rogach (Ed.), Springer-Verlag, Wien, 2008.

163. C. Frigerio et al., Anal. Chim. Acta 735 (2012).

164. P. O'Brien, N. Pickett, in The chemistry of nanomaterials: synthesis, properties and applications, C. Rao, A. Müller, A. Cheetham (Eds.), Wiley-VCH Verlag GmbH \& Co. KGaA, Weinheim, 2005.

165. Q. Song et al., Chem. Commun. 46 (2010).

166. Y. He et al., Adv. Mater. 20 (2008).

167. O. Masala, R. Seshadri, Annu. Rev. Mater. Res. 34 (2004).

168. M. Bacon, S. Bradley, T. Nann, Part. Part. Syst. Charact. 31 (2014) 04.

169. J. Peng et al., Nano Lett. 12 (2012) 02.

170. Y. Hu et al., Nanotechnology 24 (2013) 19.

171. K. Sanderson, Nature 459 (2009).

172. M. Kanehara et al., Chem. Eur. J. 18 (2012) 30.

173. H. Azzazy, M. Mansour, S. Kazmierczak, Clin. Biochem. 40 (2007) 13-14.

174. R. Hardman, Environ. Health Persp. 114 (2006) 02.

175. S. Madani et al., Int. J. Nanomedicine 8 (2013).

176. F. Mammeria et al., Colloids Surf. A 439 (2013).

177. V. Biju et al., J. Photochem. Photobiol. 183 (2006) 03.

178. B. Chen et al., J. Mater. Chem. 20 (2010).

179. M. Danilov, G. Kolbasov, Am. J. Energy Res. 1 (2013) 02.

180. D.E. Meyer, M.A. Curran, M.A. Gonzalez, J. Nanopart. Res. 13 (2010).

181. N. Krishnan et al., Environ. Sci. Technol. 42 (2008).

182. Milieu Ltd., AMEC Environment \& Infrastructure UK Ltd., Review of Environmental Legislation for the Regulatory Control of Nanomaterials Final Report No. 070307/2010/ 580540/SER/D, 2001

183. S.I. Olsen, M. Miseljic, in Proceedings of the Conference on Life Cycle Assessment in Nanotechnology - Issues in Impact Assessment and Case Studies, Barcelona, 2011.

184. A.C. Hetherington et al., Int. J. Life Cycle Assess. 19 (2014).

185. M.C. Roco, C.A. Mirkin, M.C. Hersam, Nanotechnology research directions for societal needs in 2020, Springer, New York, 2011.

186. A. Del Borghi et al., Int. J. Life Cycle Assess. 12 (2007) 01.

187. R. Hischier, PhD thesis, ETH Zurich, 2013.

188. C. Bauer et al., J. Clean. Prod. 16 (2008) 08-09.

189. S. Gavankar, S. Suh, A.F. Keller, Int. J. Life Cycle Assess. 17 (2012) 03.

190. H.C. Kim, V. Fthenakis, J. Ind. Ecol. (2012).

191. V.K.K. Upadhyayula et al., J. Clean. Prod. 26 (2012).

192. M.L. Healy, L.J. Dahlben, J.A. Isaacs, J. Ind. Ecol. 12 (2008) 03.

193. V. Khanna, N. Campion, in Nanofibers - production, properties and functional applications, T. Lin (Ed.), INTECH, Pittsburgh, 2011.
194. M. Steinfeldt, in Proceedings of Safety Issues and Regulatory Challenges of Nanomaterials in San Sebastian, Spain, 2012.

195. C. Hidalgo et al., Proceeding of the 6th International Conference on Life Cycle Management, 2013.

196. Nanoposts.com (2010). Key Products and players, global markets and applications for nanotechnology in personal care, cosmetics, household care, packaging and leisure wear \& equipment [http://www.nanoposts.com/].

197. E. Minoux, et al., Nano Lett. 5 (2005) 11.

198. K. Teo, et al., Nature 437 (2005).

199. P. Legagneux, et al., IEEE Nanotechnology 2 (2005) 00.

200. L. Gangloff, et al., Nano Lett. 4 (2004) 09.

201. C. Meyer, J. Ríos, B. Segal, Nanotechnology: the industrial revolution of the 21 st century, Fundación de la Innovación Bankinter, 2006.

202. G. Papanicolaou, et al., Meccanica (2014).

203. C.A. Charitidis, et al., Polym. Compos. 34 (2013) 11.

204. W. Bauhofer, J.Z. Kovacs, Compos. Sci. Technol. 69 (2009) 10.

205. Z. Wu, et al., Science 305 (2004) 5688.

206. L. Dai, D. Chang, Small 8 (2012).

207. E.S. Snow, et al., Science 307 (2005) 5717.

208. B. Esser, J. Schnorr, T. Swager, Angew. Chem. Int. Ed. 51 (2012) 23.

209. Z. Liu, et al., ACS Nano 1 (2007) 01.

210. M. Endo, et al., Carbon 9 (2001).

211. E. Hammel, et al., Carbon 42 (2004) 05-06.

212. Y.K. Choi, et al., Carbon 43 (2005) 10.

213. K. De Jong, J. Geus, Cat. Rev. Sci. Eng. 42 (2000) 04.

214. G. Tibbetts, et al., Compos. Sci. Technol. 67 (2007) 07-08.

215. X. Yang, et al., Int. J. Nanomedicine 9 (2014).

216. N. Gharbi, et al., Nano Lett. 5 (2005).

217. N. Durr, et al., Nano Lett. 7 (2007) 04.

218. S. Aryal, et al., J. Mater. Chem. 19 (2009).

219. A.T. Le, et al., Adv. Nat. Sci. Nanosci. Nanotechnol. 3 (2012) 04.

220. J. Kim, et al., Nanomedicine 3 (2007) 01.

221. H. Lara, et al., World J. Microb. Biot. 26 (2010) 04.

222. S. Sudrik, et al., Chem. Eur. J. 12 (2006) 03.

223. K. Bratlie, et al., Nano Lett. 10 (2007) 07.

224. D. Astruk, Eur. J. Inorg. Chem. 46 (2007) 06.

225. A. Bell, Science 299 (2003) 5613.

226. S. Pratsinis, in Aerosol science and technology: history and reviews, D.S. Ensor, K. Lohr (Eds.), RTI Press, 2011.

227. K. Clement et al., in Handbook of industrial chemistry and biotechnology, J.A. Kent (Ed.), 12nd edn., Springer, New York, 2012.

228. D. Rickerby, J. Nanosci. Nanotechnol. 7 (2007) 12.

229. C. Buzea, I.P. Blandino, K. Robbie, Biointerphases 2 (2007) 04.

230. C. Belcher et al., in Nanotechnology commercializaton, T. Tsuzuki (Ed.), Taylor \& Francis Group, LLC, 2013.

Cite this article as: Charitidis CA, Georgiou P, Koklioti MA, Trompeta A-F \& Markakis V: Manufacturing nanomaterials: from research to industry. Manufacturing Rev. 2014, 1, 11. 